NBER WORKING PAPER SERIES

\title{
PORTFOLIO CHOICE IN A MONETARY OPEN-ECONOMY DSGE MODEL
}

\author{
Charles Engel \\ Akito Matsumoto \\ Working Paper 12214 \\ http://www.nber.org/papers/w12214
}

\author{
NATIONAL BUREAU OF ECONOMIC RESEARCH \\ 1050 Massachusetts Avenue \\ Cambridge, MA 02138 \\ May 2006
}

We have benefitted from discussions with Olivier Jeanne, Karen Lewis, Alessandro Rebucci, Cedric Tille, Robert Vigfusson, Eric van Wincoop, and Frank Warnock. We also thank participants at numerous seminars. Engel acknowledges the support of the National Science Foundation through a grant to the University of Wisconsin. Some of the work on this project was completed while Engel was a visiting scholar of the International Monetary Fund, and Matsumoto was a graduate intern at the Board of Governors of the Federal Reserve System. The views expressed in this paper are those of the authors and do not necessarily represent those of the Federal Reserve System, the IMF or IMF policy. Earlier drafts of this paper were circulated under the title "Home Bias in Equities under New Open Economy Macroeconomics" and "Portfolio Choice and Home Bias in Equities in a Monetary Open-Economy DSGE Model." Engel: E-mail: cengel@ssc.wisc.edu Matsumoto: E-mail: amatsumoto@imf.org. Phone: +1-202-623-4312. The views expressed herein are those of the author(s) and do not necessarily reflect the views of the National Bureau of Economic Research.

(C2006 by Charles Engel and Akito Matsumoto. All rights reserved. Short sections of text, not to exceed two paragraphs, may be quoted without explicit permission provided that full credit, including $\odot$ notice, is given to the source. 
Portfolio Choice in a Monetary Open-Economy DSGE Model

Charles Engel and Akito Matsumoto

NBER Working Paper No. 12214

May 2006

JEL No. F31, F41, G11

\begin{abstract}
This paper develops a two-country monetary DSGE model in which households choose a portfolio of home and foreign equities, and a forward position in foreign exchange. Some goods prices are set without full information of the state. We show that temporarily sticky nominal goods prices can have large effects on equity portfolios. Home and foreign portfolios are not identical in equilibrium. In response to technology shocks, sticky prices generate a negative correlation between labor income and the profits of domestic firms, biasing portfolios in favor of home equities. In contrast, under flexible prices, labor income and the profits of the domestic firms are positively correlated. Even a small amount of nominal price stickiness can generate these portfolio differences, depending on the diversification role played by the terms of trade. Returns on human capital and equities may be positively correlated under sticky prices when the source of shocks is monetary, but this risk is hedged through nominal assets rather than through equities.
\end{abstract}

Charles M. Engel

Department of Economics

University of Wisconsin

1180 Observatory Drive

Madison, WI 53706-1393

and NBER

cengel@ssc.wisc.edu 


\section{Introduction}

In an open macroeconomy in which asset trade is possible, the portfolio choice of households may play an important role in understanding macro fluctuations. In contrast to a closed economy model - in which a representative agent simply holds the market portfolio - agents in each country may hold different portfolios depending on the country-specific risks and returns that they encounter. Portfolio choice might matter for a number of questions: Does the international transmission mechanism depend on who owns firms? Do changes in valuations of internationally traded assets play a role in the macroeconomic adjustment to shocks? Is there an interaction between the stock market and exchange rates? ${ }^{1}$

There is a long history in international finance of "portfolio balance" models of the open economy that integrate portfolio choice into an open-economy general equilibrium. Black (1973), Branson (1977), and Branson and Henderson (1985) are prominent early efforts. The earlier papers integrate asset choice into general equilibrium macro models by taking some ad hoc shortcuts. But, for example, Lucas (1982) provides a fully optimizing model of portfolio balance, in which households trade bonds, equities, and claims to monetary transfer from the government. Lucas (1982) and all subsequent fully-worked out portfolio-balance models have complete nominal goods price flexibility. However, the earlier tradition focused on sticky-price models, which might be appropriate for the consideration of the real consequences of nominal exchange rate fluctuations. There have been some attempts to incorporate optimizing portfolio choice into sticky-price macro models, ${ }^{2}$ but none of these attempts successfully nest dynamic portfolio choice in a fully-optimizing model with agents maximizing subject to explicit dynamic budget constraints and with an explicit definition of equilibrium. These models are still considered valuable tools for analyzing open economies (recent examples include Blanchard, Giavazzi, and Sa (2005) and Edwards (2005)), ${ }^{3}$ but they lack a rigorous foundation. As Obstfeld (2004, p. 557) notes, “we have no integrative general-equilibrium monetary model of international portfolio choice, although we need one.” This paper fills the gap.

But what do we learn by modeling portfolio choice in a sticky-price environment? Indeed, it would seem at first blush that price stickiness should be a minor consideration for asset demands. The value of an asset is determined by the expected present discounted value of its current and future payouts. Since persistent productivity shocks drive the real payoffs of assets, price stickiness should have only a small effect on the expected present value. One of the central insights of this paper is that transitory price stickiness can have a large impact on international asset choice. It draws on the insight that terms-of-trade changes can provide substantial insurance for productivity shocks even in

\footnotetext{
${ }^{1}$ On the first question, see for example Baxter and Crucini (1995), Kehoe and Perri (2002). Gourinchas and Rey (2005) and Tille (2004) have recently addressed the second question. Pavlova and Rigobon (2003), Andersen, Bollerslev, Diebold, and Vega (2005), and Hau and Rey (2006) are recent papers that have tried to answer the third question.

${ }^{2}$ See for example Dornbusch (1983).

${ }^{3}$ Recent examples include Blanchard, Giavazzi, and Sa (2005) and Edwards (2006).
} 
the absence of trade in assets. For example, a negative domestic productivity shock reduces the supply of home goods, but the effects of this shock on home income can be offset to some extent by an increase in the relative price of exports. If prices are flexible, portfolio diversification may not increase expected utility much because of the automatic risk diversification from the terms-of-trade adjustment. However, the risks encountered under sticky prices cannot be insured by terms-of-trade movements. While these risks may be only transitory, they might have a dominant role in portfolio choice because the equity portfolio is the only means of insuring against these shocks. When prices are sticky, the mix of home and foreign equities can differ dramatically from the mix under flexible prices, even when prices adjust relatively rapidly.

We build a symmetric, two-country model in which agents have identical preferences in each country, firms use identical technologies, market structure is identical, and the stochastic processes of the driving variables (productivity and monetary) are identical. In equilibrium, we find however that home and foreign portfolios are not identical. This occurs because we assume that claims to human capital are not traded. In fact, the equilibrium portfolio may exhibit home bias in equities.

The "home bias" puzzle is one of the major puzzles in international finance. Empirical studies have found that foreign equities comprise a small proportion of investors' portfolios. ${ }^{4}$ This finding is puzzling because it appears that investors are forgoing important opportunities for diversification of risk. $^{5}$ While there have been many suggested resolutions to the puzzle, none seem able to explain entirely the extent of home bias. Our model may contribute to an understanding of home bias. It is related to one thread of the literature that has attempted to explain home bias as a hedge against nontradable risks. ${ }^{6}$ If non-traded labor income is negatively correlated with returns to domestic equities, then domestic equities serve as a hedge for labor income. That hedging incentive leads to home bias in equity portfolios.

But there is considerable dispute over whether this could explain home bias. In neoclassical models, because labor income is correlated more with domestic firms' profits than with those of foreign firms', the optimal portfolio will be more foreign-weighted than the classical endowment model predicts, as shown in Baxter and Jermann (1997). There have been some attempts to generalize the neoclassical model to generate this negative covariance of returns to human capital and domestic equities. $^{7}$ The empirical evidence on this correlation is mixed. ${ }^{8}$

\footnotetext{
${ }^{4}$ French and Poterba (1991), Tesar and Werner (1995), and Warnock (2002), for example.

${ }^{5}$ Lewis $(1999,2000)$ surveys the literature on this puzzle and discusses the losses from non-diversification.

${ }^{6}$ For example, Eldor, Pines and Schwarz (1988), Stockman and Dellas (1989), Tesar (1993), Baxter, Jermann and King (1998), Serrat (2001) and Pesenti and van Wincoop (2002). A related analysis by Obstfeld and Rogoff (2001) argues that transactions costs to trade in international goods can help account for home bias in equities. ${ }^{7}$ Palacios-Huerta (2001) claims that a substantial fraction of home bias can be explained when the differential human capital of stockholders and non-stockholders is taken into account along with human capital frictions. Heathcote and Perri (2004) show that in a two-good model with investment that there may be home bias in an neoclassical setting. See also Jermann (2002).
} 
The second major insight of the paper is that it is not the unconditional correlation between domestic equity returns and human capital that is important. What matters is the correlation conditional on the source of the shock. In our model, the unconditional correlation between the return to human capital and the return to domestic equities (relative to foreign equities) could be positive. But home bias arises because that correlation is negative if the source of shocks is productivity.

The intuition is straightforward: If all nominal prices are sticky, in the short run the level of output is demand determined. Productivity shocks have no effect on short-run output if the firm adjusts output only in response to changes in demand. For example, if home firms experience a positive productivity shock, their demand for labor will decline. Employment and wages will fall, but profits to the firm will increase. An effective hedge against employment and wage risk is ownership of the firm. If output is demand determined, the short-run returns to labor and firm owners are negatively correlated, in contrast to the usual presumption in neoclassical models.

The fact that productivity shocks create a negative correlation between returns to workers and those to firm owners is a key implication of the model. Gali (1999) builds a closed economy model under sticky prices and shows that it can generate a fall in labor hours in response to the positive technology shock, which rarely arises in a flexible price model. ${ }^{9}$ His empirical work demonstrates that labor hours decline in response to positive technology shocks in most G7 countries.

In our model, both monetary shock and technology shocks lead to consumption risk, but monetary shocks can be hedged effectively with bond portfolios (or by taking a forward position in foreign exchange.) Unexpected changes in the relative supplies of money (at home and abroad) create nominal exchange rate changes that in turn alter the value of returns on home and foreign bonds. Monetary shocks lead to positively correlated changes in labor payments and profits, but that risk is not hedged with the equity portfolio. The unconditional correlation of returns to human capital and domestic equities relative to foreign equities may be positive or negative, depending on the relative importance of monetary or productivity shocks, but there could still be considerable home bias. This occurs in our model because of features that are not present in previous equilibrium models of international portfolio diversification. Our model has two independent sources of shocks, and a nontraded asset. Moreover, because of the role of sticky nominal goods prices, the productivity shock and the monetary shock produce opposite correlations of returns to human capital and returns to domestic equities relative to foreign equities.

Of course, nominal prices do not remain fixed forever when productivity or monetary shocks occur. Eventually an adjustment is made and neoclassical results obtain in the long run. Indeed, our model has real labor income positively correlated with productivity shocks in the long run. The degree

\footnotetext{
${ }^{8}$ Baxter and Jermann (1997) produce evidence that the covariance is positive. Botazzi, Pesenti, and van Wincoop (1996) and Pesenti and van Wincoop (2002) produce evidence to suggest that outside the US there is a weak negative correlation between returns to human capital and domestic equities.

${ }^{9}$ For example of flexible price models which generate a negative correlation, see Francis and Ramey (2005a) and Dotsey (2002).
} 
of home bias depends on the persistence of price stickiness, the persistence of productivity shocks, and the weight that households assign to future consumption. We show that home bias is greater when prices adjust more slowly, when productivity shocks (in one country relative to the other) are less persistent, and when the future is discounted more heavily. However, we emphasize that the degree of home bias also depends crucially on the elasticity of substitution between home and foreign goods. When that elasticity of substitution is near unity, the terms of trade provide nearly complete insurance for productivity shocks in the long run. In that case, the welfare gains of insuring against short-run employment risk due to price stickiness dominate long-run considerations.

Our chief aim is to provide a general equilibrium model of portfolio choice under sticky nominal prices in the open economy, not necessarily a model of home bias in equities. The literature has taken many different approaches to explain home bias. In addition to the papers cited above that consider diversification against non-tradable risks, several other avenues have been explored. One group of studies has argued that the gains from international diversification are in fact small, so that small transactions costs of diversification will lead to heavily concentrated portfolios. ${ }^{10}$ Others have claimed that acquisition of information about foreign firms is more costly than for information on home firms. ${ }^{11}$ Another set of studies shows that home bias can be explained in the context of generalized preferences or prior beliefs. ${ }^{12}$ Some claim that home bias is partly due to empirical mismeasurement. ${ }^{13}$ All of these factors may help explain home bias.

In the following sections, we present two kinds of models. The first is static. It is much easier to understand the economic forces at work in the relatively simple static model, but the intuition we arrive at here carries over to the second model which is a more realistic dynamic one. The reason the intuition carries over is that we find in the dynamic model that our asset portfolio replicates the risk sharing that would occur if a complete set of contingent claims were traded, so that investors' wealth remains constant over time.

\section{The Simple Static Model}

We build a general-equilibrium, two-country model with sticky prices. We call the countries Home and Foreign. The world population is normalized to unity; half the population lives in Home and half in Foreign. Their preferences are identical. Households provide labor and own firms through equity. Firms use labor as the only input to produce a good monopolistically, and preset their prices in

\footnotetext{
${ }^{10}$ For example, Cole and Obstfeld (1991), Tesar (1995), Butler and Joaquin (2002) and many others. However, van Wincoop $(1994,1999)$, for example, finds large unexploited gains from international risk sharing.

${ }^{11}$ For example, Kang and Stulz (1997) and Hasan and Simaan (2000). A related recent study is van Nieuwerburgh and Veldkamp (2005).

${ }^{12}$ For example, van Wincoop (1994), Aizenman (1999) as examples of the former and Pastor (2000) for the latter.

${ }^{13}$ For example, Rowland and Tesar (2004) find that multinationals may have provided diversification opportunities for some countries.
} 
the consumers' currency. Markets are segmented so that only firms can export goods. All goods are tradable and perishable. In this section, the model is static.

We adopt local currency pricing here. We observe in the data, at least for developed countries, that consumer prices are sticky in the consumers' currencies rather than in the producers' currencies. However, the pricing assumption is not particularly important in determining the equity portfolio. In fact, we would have exactly the same equity portfolio when prices are preset in producers' currencies, even though the equilibrium number of forward contracts differs. ${ }^{14}$

In our model, we consider two kinds of shocks: monetary and technology shocks. The distribution of shocks is identical between Home and Foreign.

Finally, we assume that before the realization of shocks, only forward contracts in the foreign exchange and equities are traded.

\subsection{Households}

Households in both countries have identical preferences over the consumption basket, the real money of the domestic country, and leisure. There are two stages to the household decision problem. In the first stage, households choose a portfolio position: shares of Home equities $\left(\gamma_{h}\right)$, shares of Foreign equities $\left(\gamma_{f}\right)$, and a forward position in foreign exchange $(\tilde{\delta})$. These are chosen before the resolution of uncertainty. After shocks are realized, households choose consumption, labor supply and money balances to maximize

$$
\begin{gathered}
U\left(C_{t}, \frac{M_{t}}{P_{t}}, L_{t}\right)=\frac{1}{1-\rho} C_{t}^{1-\rho}+\chi \ln \left(\frac{M_{t}}{P_{t}}\right)-\frac{\eta}{1+\psi} L_{t}^{1+\psi}, \\
\rho>1, \chi>0, \psi>0 \text {, and } \eta>0
\end{gathered}
$$

subject to the constraint:

$$
P_{t} C_{t}+M_{t}=\gamma_{h} \Pi_{t}+\gamma_{f} S_{t} \Pi_{t}^{*}+W_{t} L_{t}+\tilde{\delta}\left(S_{t}-F_{t}\right)+T r_{t} .
$$

$C_{t}$ denotes the consumption basket for Home; $M_{t}$ denotes Home money; $P_{t}$, the price index; and $L_{t}$, the labor supply. $C_{t}$ is a consumption basket of a representative Home household defined as

$$
C_{t} \equiv\left(\frac{1}{2}\right)^{1 /(\omega-1)}\left(C_{h, t}^{(\omega-1) / \omega}+C_{f, t}^{(\omega-1) / \omega}\right)^{\omega /(\omega-1)}
$$

where $\omega>0$ is the elasticity of substitution between Home produced goods and Foreign produced goods. $C_{h, t}$ is the consumption basket of Home produced goods and $C_{f, t}$ is that of Foreign produced goods:

$$
C_{h, t} \equiv\left[2^{1 / \lambda} \int_{0}^{1 / 2} C_{h, t}(i)^{(\lambda-1) / \lambda} d i\right]^{\lambda /(\lambda-1)}, \quad C_{f, t} \equiv\left[2^{1 / \lambda} \int_{1 / 2}^{1} C_{f, t}(i)^{(\lambda-1) / \lambda} d i\right]^{\lambda /(\lambda-1)},
$$

\footnotetext{
${ }^{14}$ See Matsumoto (2004).
} 
where $\lambda$ denotes the elasticity of substitution among varieties, with $\lambda>1$. Then we can write the CPI as follows:

$$
P_{t} \equiv\left(\frac{1}{2}\right)^{1 /(1-\omega)}\left(P_{h, t}^{1-\omega}+P_{f, t}^{1-\omega}\right)^{1 /(1-\omega)},
$$

where

$$
P_{h, t} \equiv\left[2 \int_{0}^{1 / 2} P_{h, t}(i)^{1-\lambda} d i\right]^{1 /(1-\lambda)}, \quad P_{f, t} \equiv\left[2 \int_{1 / 2}^{1} P_{f, t}(i)^{1-\lambda} d i\right]^{1 /(1-\lambda)},
$$

where $P_{h, t}(i)$ is the price of Home goods $i$ sold in Home in terms of the Home currency, and $P_{f, t}(i)$ is the price of Foreign goods $i$ sold in Home in terms of the Home currency.

Home households receive the following: wages ( $W_{t} L_{t}$, where $W_{t}$ denotes the wage); dividends; transfers from the government $\left(T r_{t}\right)$ and the gains or losses from forward contracts. Equity dividends received by a Home household are given by

$$
\gamma_{h} \Pi_{t}+\gamma_{f} S_{t} \Pi_{t}^{*},
$$

where $\Pi_{t}$ is the profit (dividend) of Home firms and $\Pi_{t}^{*}$ is that of Foreign firms in terms of the Foreign currency. ${ }^{15} S_{t}$ is the Home currency price of Foreign currency. Home and Foreign households trade forward contracts in the foreign exchange. The forward rate, $F_{t}$, is known at the time the forward contract is entered into, prior to the realization of shocks. After the shocks are realized, the Home households receive $\tilde{\delta}\left(S_{t}-F_{t}\right)$ units of Home currency.

Foreign households have an analogous utility function for Foreign quantities and prices, which we will denote by superscript asterisks. Foreign prices are denominated in Foreign currency.

Prior to the realization of shocks, the households choose the portfolio position to maximize expected utility ( $\left.E_{t-1} U\left(C_{t}, \frac{M_{t}}{P_{t}}, L_{t}\right)\right)^{16}$ subject to the constraint:

$$
\gamma_{h}+\gamma_{f}=1
$$

Note that there is no constraint on the forward position, $\tilde{\delta}$. We assume that the ex ante distribution of shocks are identical between Home and Foreign. This assumption, together with the assumptions of identical size and identical preferences, gives us an equilibrium in which the equity prices of Home and Foreign firms are the same prior to the realization of shocks. ${ }^{17}$ In our normalization, the representative household of each country is endowed with an ownership share of 1 of their own firms,

\footnotetext{
${ }^{15}$ Theoretically, profits can be negative in the case of a loss, but we have to assume that the profits of both Home firms and Foreign firms are positive to take logarithms.

${ }^{16}$ We use the notation that expectations are taken at time t- 1 in this section - even though the model is static for notational convenience so that we can refer to some of the same equations that arise in the dynamic model.

${ }^{17}$ If prices are different, then one country is richer than the other ex ante, a situation that contradicts symmetry.
} 
but they may trade some of their shares with households in the other country, which implies constraint

(2.7). Given the symmetry in the model, there is home bias when $\gamma_{f}<\frac{1}{2}$.

Given prices and the total consumption basket, $C_{t}$, the optimal consumption allocations are

$$
\begin{gathered}
C_{h, t}=\frac{1}{2}\left(\frac{P_{h, t}}{P_{t}}\right)^{-\omega} C_{t}, \quad C_{f, t}=\frac{1}{2}\left(\frac{P_{f, t}}{P_{t}}\right)^{-\omega} C_{t}, \\
C_{h, t}(i)=2\left(\frac{P_{h, t}(i)}{P_{h, t}}\right)^{-\lambda} C_{h, t}, \quad C_{f, t}(i)=2\left(\frac{P_{f, t}(i)}{P_{f, t}}\right)^{-\lambda} C_{f, t} .
\end{gathered}
$$

The remaining first order conditions are

$$
\begin{gathered}
\frac{M_{t}}{P_{t}}=\chi C_{t}^{\rho}, \\
W_{t}=\frac{\eta}{\chi} M_{t} L_{t}^{\psi}, \\
E_{t-1}\left(S_{t} \frac{C_{t}^{-\rho}}{P_{t}}\right)=F_{t} E_{t-1}\left(\frac{C_{t}^{-\rho}}{P_{t}}\right), \\
E_{t-1}\left(\Pi_{t} \frac{C_{t}^{-\rho}}{P_{t}}\right)=E_{t-1}\left(S_{t} \Pi_{t}^{*} \frac{C_{t}^{-\rho}}{P_{t}}\right) .
\end{gathered}
$$

\subsection{Firms}

Firms engage in monopolistic competition as in Blanchard and Kiyotaki (1987). A firm in this economy monopolistically produces a specific good indexed by $i$ using a linear technology: ${ }^{18}$

$$
Y_{t}(i)=A_{t} L_{t}(i) \text {, }
$$

where $Y_{t}(i)$ is the production of firm $i, A_{t}$ is the country-specific technology parameter and $L_{t}(i)$ is the labor input of firm $i$. Labor is assumed to be homogeneous and to be supplied elastically. Home and Foreign markets are segmented, and only the producer can distribute its product. Firms set prices one period in advance in the consumers' currencies for each country. Firms in each country set prices so as to maximize their expected profits, taking other firms' prices as given, which is equivalent to taking the price level as given since each firm has measure zero on interval $[0,1]$.

Given the CES utility sub-function, the demand for Home good $i$ from the Home market denoted by $Y_{h, t}(i)$ is

$$
Y_{h, t}(i)=\left(\frac{P_{h, t}(i)}{P_{h, t}}\right)^{-\lambda}\left(\frac{P_{h, t}}{P_{t}}\right)^{-\omega} C_{t},
$$

\footnotetext{
${ }^{18}$ Using a Cobb-Douglas technology with other fixed inputs will not change the result if the returns on the other factors belong to the equity holders.
} 
while the demand for Home good $i$ from the Foreign market is

$$
Y_{h, t}(i)^{*}=\left(\frac{P_{h, t}^{*}(i)}{P_{h, t}^{*}}\right)^{-\lambda}\left(\frac{P_{h, t}^{*}}{P_{t}^{*}}\right)^{-\omega} C_{t}^{*} .
$$

Firm $i$ 's profit maximization problem is

$$
\max _{P_{h, t}(i), P_{h, t}^{*}(i)} E_{t-1}\left\{\tilde{D}_{t}(i)\left[P_{h, t}(i) Y_{h, t}(i)+S_{t} P_{h, t}^{*}(i) Y_{h, t}^{*}(i)-\frac{W_{t}}{A_{t}}\left(Y_{h, t}(i)+Y_{h, t}^{*}(i)\right)\right]\right\},
$$

where $\tilde{D}_{t}(i)$ is the stochastic discount factor for the firm $i$. For example, if firms are owned by Home residents, it will be $\frac{C_{t}^{-\rho}}{P_{t}}$. However, because firms are not always domestically owned, we use a more general notation.

The optimal price of Home goods for the Home market is ${ }^{19}$

$$
P_{h, t}=\frac{\lambda}{\lambda-1} \frac{E_{t-1}\left(\tilde{D}_{t} C_{t} \frac{W_{t}}{A_{t}}\right)}{E_{t-1}\left(\tilde{D}_{t} C_{t}\right)} .
$$

Similarly, the optimal price of Home goods for the Foreign market is

$$
P_{h, t}^{*}=\frac{\lambda}{\lambda-1} \frac{E_{t-1}\left(\tilde{D}_{t} C_{t}^{*} \frac{W_{t}}{A_{t}}\right)}{E_{t-1}\left(\tilde{D}_{t} C_{t}^{*} S_{t}\right)} .
$$

Because firms are all alike, they will set the identical prices for each market.

The market clearing condition can be obtained by equating the output with the sum of the demands for Home goods:

$$
A_{t} L_{t}=\frac{1}{2}\left(\frac{P_{h, t}}{P_{t}}\right)^{-\omega} C_{t}+\frac{1}{2}\left(\frac{P_{h, t}^{*}}{P_{t}^{*}}\right)^{-\omega} C_{t}^{*} .
$$

Given these prices, we can calculate profits. Using the optimal consumption allocations, we can write the profits for the firms in each country in terms of the Home currency as

$$
\begin{gathered}
\Pi_{t}=\frac{1}{2} P_{h, t}\left(\frac{P_{h, t}}{P_{t}}\right)^{-\omega} C_{t}+\frac{1}{2} S_{t} P_{h, t}^{*}\left(\frac{P_{h, t}^{*}}{P_{t}^{*}}\right)^{-\omega} C_{t}^{*}-W_{t} L_{t}, \\
S_{t} \Pi_{t}^{*}=\frac{1}{2} S_{t} P_{f, t}^{*}\left(\frac{P_{f, t}^{*}}{P_{t}^{*}}\right)^{-\omega} C_{t}^{*}+\frac{1}{2} P_{f, t}\left(\frac{P_{f, t}}{P_{t}}\right)^{-\omega} C_{t}-S_{t} W_{t}^{*} L_{t}^{*} .
\end{gathered}
$$

Firms will pay out all of their profits as dividends.

We assume that $A_{t}$ and $A_{t}^{*}$ are drawn from identical lognormal distributions with $\operatorname{var}_{t-1}\left(\ln \left(A_{t}\right)\right)=\operatorname{var}_{t-1}\left(\ln \left(A_{t}^{*}\right)\right)=\sigma_{a}^{2}$, and $\operatorname{cov}_{t-1}\left(\ln A_{t} \ln A_{t}^{*}\right)=\sigma_{a, a^{*}}$. We also assume that $M_{t}$ and $M_{t}^{*}$

\footnotetext{
${ }^{19}$ We will omit index $i$ since Home firms are identical.
} 
are drawn from identical lognormal distributions with $\operatorname{var}_{t-1}\left(\ln \left(M_{t}\right)\right)=\operatorname{var}_{t-1}\left(\ln \left(M_{t}^{*}\right)\right)=\sigma_{m}^{2}$, and $\operatorname{cov}_{t-1}\left(\ln M_{t}, \ln M_{t}^{*}\right)=\sigma_{m, m^{*}}$

The labor market is competitive, and the wage moves freely to equate demand and supply of labor after the shocks. The output of each good is determined by demand. Firms adjust output after the shocks to satisfy demand, holding prices constant. The money market is assumed to equilibrate, so money demand equals money supply.

\subsection{Solution of the Static Model}

An equilibrium in the static model satisfies equations (2.2) and (2.5)-(2.21), and their foreign counterparts. These 39 equations (one is redundant by Walras' Law) solve for $C_{t}, C_{h, t}, C_{f, t}, C_{h, t}(i)$, $C_{f, t}(i), L_{t}, W_{t}, P_{t}, P_{h, t}, P_{f, t}, P_{h, t}(i), P_{h, t}^{*}(i), Y_{t}(i), Y_{h, t}(i), Y_{h, t}^{*}(i), \Pi_{t}, \gamma_{h}, \gamma_{f}$, and their foreign counterparts, and $\tilde{\delta}, F_{t}$, and $S_{t} \cdot{ }^{20}$

We will not in fact solve for this equilibrium, but will instead solve the equilibrium for a set of equations that approximate these 39. We take first-order approximations to the budget constraint (2.2), the definitions of the consumption and price indexes (2.3)-(2.6), the equilibrium condition (2.19), and the definition of profits (2.20)-(2.21). Under our assumption that the driving variables are lognormally distributed, and with the log-linearization of these equations, we can solve equations (2.7)-(2.18) exactly. By exactly solving the Euler equations (2.12)-(2.13), we have successfully integrated international portfolio choice into a sticky-price model.

Our focus is on the equilibrium portfolio choice of equity shares and forward foreign exchange position. We proceed in this section to construct the equilibrium solutions for these variables in an intuitive manner. We will first derive the portfolio demands for households, taking prices as given. With these in hand, we will use equilibrium conditions in goods, labor, and asset markets to derive the equilibrium portfolio positions.

We rely on ex ante symmetry in the derivations below. Lower-case letters refer to logs of their upper case counterparts. We use "var" to denote variance, and "cov" covariance. ${ }^{21}$ We use the notation $\bar{x}=E\left(x_{t}\right)$. In the linearized equations below, we suppress the intercept terms for convenience.

Under log-normality, the household first-order condition (2.12) can be written as

$$
-\rho \operatorname{cov}\left(c_{t}, s_{t}\right)+\frac{1}{2} \operatorname{var}\left(s_{t}\right)=0
$$

\footnotetext{
${ }^{20}$ We have also implicitly assumed that there is a money market equilibrium condition, but we have not introduced separate notation for money demand and money supply and that there is a forward market clearing condition which can be guaranteed here by setting $\tilde{\delta}^{*}=F \tilde{\delta}$. By symmetry in the static model, $F$ equals one.

${ }^{21}$ We drop the $t-1$ subscript on expectations for the rest of this section.
} 
where we have used ex ante symmetry to give us $f_{t}=0$, and $E\left(s_{t}\right)=0$.

We can use similar steps, and recognize that symmetry implies that $\bar{\pi}=\bar{\pi}^{*}, \operatorname{var}\left(\pi_{t}\right)=\operatorname{var}\left(\pi_{t}^{*}\right)$, and $\operatorname{cov}\left(s_{t}, \pi_{t}\right)=-\operatorname{cov}\left(s_{t}, \pi_{t}^{*}\right)$, to derive from equation (2.13):

$$
\rho \operatorname{cov}\left(c_{t}, \pi_{t}-\left(s_{t}+\pi_{t}^{*}\right)\right)-\frac{1}{2} \operatorname{cov}\left(s_{t}, \pi_{t}-\left(s_{t}+\pi_{t}^{*}\right)\right)=0 .
$$

We approximate the budget constraint (2.2), using condition (2.7) to arrive at

$$
p_{t}+c_{t}=(1-\gamma)(1-\zeta) \pi_{t}+\gamma(1-\zeta)\left(s_{t}+\pi_{t}^{*}\right)+\zeta\left(w_{t}+l_{t}\right)+\delta s_{t},
$$

where $\zeta \equiv \frac{e^{\bar{w}+\bar{l}}}{e^{\bar{\pi}}+e^{\bar{w}+\bar{l}}}, \delta \equiv \frac{\tilde{\delta}}{e^{\bar{\pi}}+e^{\bar{w}+\bar{l}}}$, and $\gamma \equiv \gamma_{f}$. Here, we have approximated the budget constraint around a point where $x_{t}=\bar{x}$ for $x_{t}=s_{t}, c_{t}, \pi_{t}, \pi_{t}^{*}, w_{t}, l_{t}$.

We use equation (2.24) to substitute out for $c_{t}$ in equations (2.22) and (2.23), and recognize that $p_{t}$ is predetermined. Using these equations, we solve out for $\gamma$ and $\delta$ :

$$
\gamma=\frac{\operatorname{cov}\left(\pi_{t}-\beta_{\pi, s} s_{t}, \pi_{t}-\pi_{t}^{*}\right)}{\operatorname{var}\left(\pi_{t}-\pi_{t}^{*}-\beta_{\pi-\pi^{*}, s} s_{t}\right)}+\frac{\zeta}{1-\zeta} \frac{\operatorname{cov}\left(w_{t}+l_{t}-\beta_{w+l, s} s_{t}, \pi_{t}-\pi_{t}^{*}\right)}{\operatorname{var}\left(\pi_{t}-\pi_{t}^{*}-\beta_{\pi-\pi^{*}, s} s_{t}\right)}
$$

where we have used the notation $\beta_{x, s} \equiv \frac{\operatorname{cov}\left(x_{t}, s_{t}\right)}{\operatorname{var}\left(s_{t}\right)}$

Consider expression (2.25). From the household's point of view, the equity position is determined by the covariances and variances of shocks to profits and labor income that are orthogonal to exchange rates. Any variance in the portfolio that is attributable to exchange rate changes is hedged through the forward position, so the equity position is determined only by those risks that are uncorrelated with exchange rate risk.

If the component of labor income that is orthogonal to exchange rates were uncorrelated with relative profits of Home and Foreign firms (or if labor's share were zero), the second term in equation (2.25) would drop out. Then the share $\gamma$ of equities held in Foreign firms would increase as Home profits (orthogonal to the exchange rate) have a higher covariance with relative Home and Foreign profits. Under our symmetry assumption, this term will equal 1/2, so the portfolio would be balanced between Home and Foreign equities if only the first term mattered. It is the second term of equation (2.25) that will determine home bias.

That term tells us that the share of Foreign equities will be larger the greater the covariance between wage income and Home profits relative to Foreign profits. If this covariance is positive, there will be anti-home bias $\left(\gamma>\frac{1}{2}\right)$, as in Baxter and Jermann (1997). In that case, returns to Home equities (compared to returns on Foreign equities) are positively correlated with labor income, so the 
variance of total income (returns to equities and human capital) is reduced by holding a relatively large share of Foreign equities. There is home bias when that covariance is negative. In that case, Home equities serve as a hedge against labor income shocks.

So far, to arrive at equation (2.25), we have only used the households' first-order conditions and budget constraints, along with the symmetry assumption and the assumption that nominal prices are fixed. Now we can bring in one more equation from the rest of the economy, the linearization of the profit equation for Home firms. We have from (2.20)

$$
(1-\zeta) \pi_{t}+\zeta\left(w_{t}+l_{t}\right)=p_{t}+c_{t}^{W}+\frac{1}{2} s_{t},
$$

where $c_{t}^{W}=\frac{1}{2}\left(c_{t}+c_{t}^{*}\right) \cdot^{22}$

Taking covariances with $\pi_{t}-\pi_{t}^{*}$ on both sides of equation (2.26), we get

$$
\operatorname{cov}\left(\pi_{t}+\frac{\zeta}{1-\zeta}\left(w_{t}+l_{t}\right), \pi_{t}-\pi_{t}^{*}\right)=\frac{1}{2(1-\zeta)} \operatorname{cov}\left(s_{t}, \pi_{t}-\pi_{t}^{*}\right),
$$

where we have used symmetry to infer that $\operatorname{cov}\left(c_{t}^{W}, \pi_{t}-\pi_{t}^{*}\right)=0$. Also,

$$
\operatorname{cov}\left(\pi_{t}+\frac{\zeta}{1-\zeta}\left(w_{t}+l_{t}\right), s_{t}\right)=\frac{1}{2(1-\zeta)} \operatorname{var}\left(s_{t}\right)
$$

using symmetry to infer that $\operatorname{cov}\left(c_{t}^{W}, s_{t}\right)=0$. Dividing through by $\operatorname{var}\left(s_{t}\right)$, we can write $\beta_{\pi, s}+\frac{\zeta}{1-\zeta} \beta_{w+l, s}=\frac{1}{2(1-\zeta)}$. Substitute these relations into the right-hand side of (2.25) to derive $\gamma=0$.

We can then get the equilibrium value of $\delta$, when $\gamma=0$ :

$$
\delta=-\frac{1}{2}+\frac{1}{2 \rho} .
$$

We find complete home bias in equity holdings, $\gamma=0$. Equation (2.25) indicates that the share of equities held in the foreign firm is determined by the covariance of the component of Home firm revenues $(1-\zeta) \pi_{t}+\zeta\left(w_{t}+l_{t}\right)$ that is orthogonal to the exchange rate with the relative profits of Home to Foreign firms. If that covariance is zero, then no foreign equities are held. In that case, returns to Home equities are a perfect hedge for labor income.

In fact, the residual from projecting $(1-\zeta) \pi_{t}+\zeta\left(w_{t}+l_{t}\right)$ on $s_{t}$ is orthogonal to $\pi_{t}-\pi_{t}^{*}$. That is because equation (2.26) tells us that the revenue of the Home firm, $(1-\zeta) \pi_{t}+\zeta\left(w_{t}+l_{t}\right)$, is

\footnotetext{
22 In deriving (2.26), we use symmetry to get $\bar{c}=\bar{c}^{*}$ and $p_{t}=p_{t}^{*}$. The Appendix shows that $p_{h t}-p_{t}=0$, which we have used to derive (2.26).
} 
determined by world consumption and the exchange rate: $c_{t}^{W}+\frac{1}{2} s_{t}$. Output is demand determined. Demand depends on the overall level of consumption in both countries. Additionally, the Homecurrency revenue of the Home firm increases when the currency depreciates, because the depreciation increases the Home-currency value of Foreign sales. The projection residual is simply world consumption, $c_{t}^{W}$, and that is uncorrelated with relative profits by symmetry.

Note that if we substitute the solutions for $\gamma$ and $\delta$ back into the budget constraint, we obtain

$$
p_{t}+c_{t}=(1-\zeta) \pi_{t}+\zeta\left(w_{t}+l_{t}\right)+\left(\frac{1}{2 \rho}-\frac{1}{2}\right) s_{t}=p_{t}+c_{t}^{W}+\frac{1}{2 \rho} s_{t} .
$$

Using the definition of world consumption, this expression can be written as

$$
\rho c_{t}=s_{t}+\rho c_{t}^{*} .
$$

This condition indicates that the linearized model replicates the equilibrium in which a full set of nominal contingent bonds is traded. As is well known, in this case (and assuming symmetry), the marginal utility of a unit of Home (or Foreign) currency is equalized between home and foreign residents:

$$
\frac{C_{t}^{-\rho}}{P_{t}}=\frac{C_{t}^{*-\rho}}{S_{t} P_{t}^{*}}
$$

Equation (2.28) takes the $\log$ of this condition, using symmetry to infer $p_{t}=p_{t}^{*}$. The trading of Home and Foreign equities and forward contracts for foreign exchange are enough to deliver the same allocation as trading a full set of nominal contingent claims in the linearized economy. ${ }^{23}$

We have derived the complete home bias result using only the nominal price stickiness assumption, the definition of Home profits, the budget constraint of Home households, and the two first-order conditions (2.12 and 2.13) that pertain to asset choice. (The derivations in this subsection all arise from equations (2.22), (2.23), (2.24), and (2.26), which are the approximated versions of the two first-order conditions for asset choice, the household budget constraint, and the definition of firm profits. In performing the approximations, we have used the fact that prices are preset.)

We have not relied on other features of the model, so our home bias result is robust to alternative assumptions. For example, the result does not depend on money demand arising from real balances in the utility function. Other specifications that maintain equations (2.12) and (2.13) will deliver the same result.

As long as symmetry is maintained, the result does not depend on the assumptions about monetary policy. In particular, we emphasize that our result does not depend on any assumption about the correlation of money shocks and productivity shocks. The reason is that forward contracts

\footnotetext{
${ }^{23}$ Note the implication that the factor firms use in equations (2.17) and (2.18) to discount expected profits is identical (up to the linear approximation) for home and foreign households.
} 
fully hedge monetary policy innovations, regardless of their correlation with innovations to technology. That is because, as we show below, the exchange rate is determined by relative money supplies.

The result also does not depend on our specification of the labor market as competitive with flexible wages. For example, a sticky-wage model in which employment was demand determined would not alter the conditions that we used in the derivation of the home-bias result. The key point is that when nominal prices are set in advance, revenue earned by the firm does not depend on the realization of productivity. The quantity produced by the firm is determined by demand, and the price is set in advance, so price times quantity does not respond to technology shocks. Full hedging of technology shocks would then require households to hold only the domestic equity. Any decline in employment income arising from productivity changes - whether it be from falling wages, or reduced hours, or some combination - is completely offset in profits to the firm.

Further insights can be obtained from making use of some of the other equations of the model. Specifically, the first-order condition for holdings of money balances (and again using the fact that nominal prices are preset), is written as

$$
m_{t}=\rho c_{t} .
$$

Using this equation along with its foreign counterpart, and equation (2.28), we derive

$$
s_{t}=m_{t}-m_{t}^{*} \text {. }
$$

Exchange rates are determined by relative money supplies.

The fact that equity demand depends only on the covariances after projecting on the exchange rate means that the equity portfolio is used only to hedge productivity shocks. Productivity shocks do not influence the amount of product the firm sells, which is demand determined in a stickyprice model. Nor do productivity shocks affect the exchange rate, which influences firm revenue as well. So firm revenue depends only on monetary shocks. A positive productivity shock, for example, allows the firm to produce the quantity demanded with less labor. Both wages and employment fall in equilibrium. Profits increase by the exact amount of the drop in labor income. But the effect of those shocks on household income is fully hedged when Home households hold 100 percent of Home firms.

Monetary shocks have real consequences in this model. Indeed, equation (2.29) shows that in equilibrium, consumption is determined only by money supplies. As we have noted, productivity shocks only affect the distribution of revenues between labor income and profits, but in equilibrium, the effects of that redistribution is nullified by the complete home bias in equity holdings. The real effects of monetary shocks are hedged through the forward position in foreign exchange.

Suppose, for example, that there is a negative Home monetary shock. In equilibrium, income of Home households falls because both labor and profit income fall. But the drop in the Home money supply also causes a home currency appreciation ( $s_{t}$ declines.) The equilibrium value of $\delta$ is negative, given our assumption of $\rho>1$. In this case, a decline in $s_{t}$ leads to a positive payoff from the forward 
position. That is, when $\delta$ is negative, the Home resident is short in foreign currency and long in home currency. So an appreciation yields a positive payoff, which hedges the effects of monetary shocks on labor and profit income.

Notice that the forward position does not completely eliminate the effects of monetary shocks on income. From equation (2.26), we have that $(1-\zeta) \pi_{t}+\zeta\left(w_{t}+l_{t}\right)$ falls by $\frac{1}{2 \rho}+\frac{1}{2}$ times the decrease in $m_{t}$ (because $c_{t}^{W}$ falls by $\frac{1}{2 \rho}$ and $\frac{1}{2} s_{t}$ by $\frac{1}{2}$.) Including returns from the forward position solved from equation (2.27), $\delta=\frac{1}{2 \rho}-\frac{1}{2}$, we find that income still falls by $\frac{1}{\rho}$ times the drop in $m_{t}$. Why? In this model, the Home and Foreign consumption markets are completely segmented. A change in the exchange rate causes a change in the relative prices paid by Home and Foreign households for identical goods, because nominal prices are set in advance in consumers' currencies and do not respond to shocks. So Home prices rise relative to Foreign prices (expressed in a common currency) when $s_{t}$ falls. But households cannot trade goods to arbitrage the difference in goods prices. As is well known, when consumer products are not tradable, the efficient configuration of consumption (achievable when a full set of contingent nominal bonds is traded) has consumption levels lower in the Home country (relative to the Foreign country) in those states of the world in which its goods prices are higher than those in the Foreign country. That is why the equilibrium condition (2.29) does not achieve perfect consumption correlation. So with a negative Home monetary shock, ceteris paribus, Home income falls and Home consumption declines.

\section{Dynamic Model}

In this section, we build an infinite-horizon model, which allows us to examine the effects of persistent technology shocks and different degrees of price stickiness. Most of the assumptions are the same as in the static model.

The price-setting rule is modified as follows. A fraction $\tau$ of firms in each country set prices in advance, and the rest of the firms can adjust their prices in each period after the realization of shocks. This approach allows us to study the portfolio allocation with or without sticky prices, and we can learn how different degrees of price stickiness affect the portfolio. There are different types of firms in each country but we assume the equities of all firms in each country are bundled together.

We address two important questions here. First, does price stickiness matter much for international portfolio choice? In a world with temporary price stickiness and persistent productivity shocks, one might expect the answer is no. But we will show that in fact a small amount of price stickiness may matter a lot. Second, how do persistent shocks affect the optimal portfolio? In a 
flexible price setting, the optimal portfolio is more foreign skewed than it is in the classic endowment economy case, as shown in Baxter and Jermann (1997). This effect decreases the degree of home bias in our model as well. In the dynamic model, when the elasticity of substitution between Home and Foreign goods is more than unity ( $\omega>1)$, the optimal Home portfolio should be less home biased than it is in the static model because households must take into account the future after prices have been adjusted.

We have shown that we can integrate international portfolio choice into a monetary model by exactly solving the Euler equations as discussed in static model. Our model exhibits stationarity in the linearized economy by replicating the real-side allocations of a model with a full set of nominal contingent claims, although in our model we have only equities and forward contacts. As shown in the Appendix, Home and Foreign equities and forward contracts span the linear space generated by relative shocks in the linearized economy.

\subsection{Household Problem}

Home households maximize their expected utility:

$$
\max E_{0} \sum_{t=0}^{\infty} \beta^{t} U\left(C_{t}, \frac{M_{t}}{P_{t}}, L_{t}\right)
$$

subject to the following budget constraint:

$$
\begin{aligned}
& P_{t} C_{t}+M_{t}+Q_{t} \gamma_{h, t+1}+S_{t} Q_{t}^{*} \gamma_{f, t+1} \\
& =\gamma_{h, t}\left(Q_{t}+\Pi_{t}\right)+\gamma_{f, t} S_{t}\left(Q_{t}^{*}+\Pi_{t}^{*}\right)+\left(S_{t}-F_{t}\right) \tilde{\delta}_{t}+W_{t} L_{t}+M_{t-1}+T r_{t}
\end{aligned}
$$

where $Q_{t}\left(Q_{t}^{*}\right)$ denotes the price of Home (Foreign) equities. The utility function and consumption baskets are the same as in the static model. Households enter time $t$ with money $M_{t-1}$, equities $\left(\gamma_{h, t}, \gamma_{f, t}\right)$, and forward contracts $\tilde{\delta}_{t}$. After the realization of shocks, households choose the consumption level, real money balances, and labor supply. The dividends from firms are paid at time $t$, and households get the payoff from the forward contract. They receive the transfer from the

government as well. Finally, the households choose forward contracts $\tilde{\delta}_{t+1}$ and equity holdings $\gamma_{h, t+1}$, $\gamma_{f, t+1}$, which determine the dividends households receive at time $t+1$.

Our assumptions on consumption, asset acquisition, etc., follow exactly the standard presentation of the non-stochastic dynamic model (see, for example, Obstfeld and Rogoff (1996)), with one exception: We assume, as in the static model, that households can take a forward position in foreign exchange. Making a contract to buy foreign exchange forward next period, of course, is equivalent to buying a nominal (non-state-contingent) bond denominated in the foreign currency and shorting a nominal bond denominated in the home currency. We could have introduced nominal bonds denominated in each currency separately into the model, rather than forward contracts. 
However, that would add nothing to our presentation. We shall see below that the (linearized) model with equities and forward contracts reproduces the allocation that would be achieved with trade in a complete set of nominal state-contingent bonds. So, if we introduced non-state-contingent nominal bonds instead of forward contracts, we know that the position held by each household will exactly reproduce their position in the forward market.

The first order conditions for the households are

$$
\begin{gathered}
\frac{\chi}{M_{t}}=\frac{C_{t}^{-\rho}}{P_{t}}-E_{t} \beta \frac{C_{t+1}^{-\rho}}{P_{t+1}}, \\
\eta L_{t}^{\psi}=\frac{C_{t}^{-\rho}}{P_{t}} W_{t}, \\
E_{t-1}\left(\frac{C_{t}^{-\rho}}{P_{t}} S_{t}\right)=F_{t} E_{t-1}\left(\frac{C_{t}^{-\rho}}{P_{t}}\right), \\
\frac{C_{t-1}^{-\rho}}{P_{t-1}} Q_{t-1}=E_{t-1}\left(\beta \frac{C_{t}^{-\rho}}{P_{t}}\left(Q_{t}+\Pi_{t}\right)\right), \\
\frac{C_{t-1}^{-\rho}}{P_{t-1}} S_{t-1} Q_{t-1}^{*}=E_{t-1}\left(\beta \frac{C_{t}^{-\rho}}{P_{t}} S_{t}\left(Q_{t}^{*}+\Pi_{t}^{*}\right)\right) .
\end{gathered}
$$

First, let $D_{t, t+s} \equiv\left(\frac{C_{t+s}^{-\rho}}{P_{t+s}}\right) /\left(\frac{C_{t}^{-\rho}}{P_{t}}\right)$. The no-bubble solution for equity prices implies that

$$
Q_{t}=\sum_{s=1}^{\infty} E_{t} \beta^{s} D_{t, t+s} \Pi_{t+s}, \quad S_{t} Q_{t}^{*}=\sum_{s=1}^{\infty} E_{t} \beta^{s} D_{t, t+s} S_{t+s} \Pi_{t+s}^{*}
$$

Let

$$
\begin{gathered}
V_{t} \equiv \gamma_{h, t+1} Q_{t}+\gamma_{f, t+1} S_{t} Q_{t}^{*}, \\
H_{t} \equiv \sum_{s=1}^{\infty} \beta^{s} E_{t} D_{t, t+s} W_{t+s} L_{t+s}, \\
R_{t} \equiv \frac{\beta\left(Q_{t}+\Pi_{t}\right)}{Q_{t-1}}, \\
R_{t}^{H} \equiv \frac{\beta\left(H_{t}+W_{t} L_{t}\right)}{H_{t-1}}, \\
\gamma_{t+1} \equiv \frac{\gamma_{f, t+1} S_{t} Q_{t}^{*}}{V_{t}}=1-\frac{\gamma_{h, t+1} Q_{t}}{V_{t}} .
\end{gathered}
$$

These are, respectively, financial wealth, human capital, the rate of return on financial wealth and human capital (each multiplied by the utility discount factor for algebraic convenience) and the share of foreign equity in equity portfolio.

We can rewrite the budget constraint (3.1) for time $t$ : 


$$
P_{t} C_{t}+V_{t}+H_{t}=V_{t-1}\left(1-\gamma_{t}\right) \beta^{-1} R_{t}+V_{t-1} \gamma_{t} \beta^{-1} \frac{S_{t}}{S_{t-1}} R_{t}^{*}+H_{t-1} \beta^{-1} R_{t}^{H}+\tilde{\delta}_{t}\left(S_{t}-F_{t}\right)
$$

We will assume below a process for the money supply in which $E_{t}\left(M_{t+1}^{-1}\right)=M_{t}^{-1}$. We note this now, because under this assumption the first-order condition (3.2) can be simplified directly to get

$$
\frac{C_{t}^{-\rho}}{P_{t}}=\chi M_{t}^{-1}+E_{t} \beta \frac{C_{t+1}^{-\rho}}{P_{t+1}}=\frac{\chi}{1-\beta} M_{t}^{-1} .
$$

It follows from this that $D_{t, t+s}=\frac{M_{t}}{M_{t+s}}$. The first order conditions for equity holdings, (3.5) and (3.6), can be summarized as

$$
E_{t-1}\left(\frac{M_{t-1}}{M_{t}} R_{t}\right)=E_{t-1}\left(\frac{M_{t-1}}{M_{t}} \frac{S_{t}}{S_{t-1}} R_{t}^{*}\right)=1
$$

\subsection{Firms}

Firms use the same linear technology as in the previous section. We have two types of firms in each country. A fraction $\tau$ of firms set the price in advance, and the rest set the price after the realization of shocks. The profit maximization problem of the Home firm with price flexibility is

$$
\max P_{h, t}(i) Y_{h, t}(i)+S_{t} P_{h, t}^{*}(i) Y_{h, t}^{*}(i)-\left(\frac{W_{t}}{A_{t}}\right)\left[Y_{h, t}(i)+Y_{h, t}^{*}(i)\right] .
$$

Because $Y_{h, t}(i)$ is not a function of $P_{h, t}^{*}(i)$, and $Y_{h, t}^{*}(i)$ is not a function of $P_{h, t}(i)$, the problem is easy to solve:

$$
P_{h, t}(i)=\frac{\lambda}{\lambda-1} \frac{W_{t}}{A_{t}} \equiv P_{f l e x, h, t}, \quad P_{h, t}^{*}(i)=\frac{\lambda}{\lambda-1} \frac{W_{t}}{A_{t} S_{t}} \equiv P_{f l e x, h, t}^{*},
$$

where $P_{f l e x, h, t}$ is the optimal price for the Home market of the Home goods produced by the firms that can adjust prices after they observe shocks. $P_{f l e x, h, t}^{*}$ is the optimal price for the Foreign market.

The other optimal prices are

$$
\begin{gathered}
P_{\text {preset }, h, t} \equiv \frac{\lambda}{\lambda-1} \frac{E_{t-1}\left[\tilde{D}_{t} \frac{W_{t}}{A_{t}}\left(\frac{1}{P_{h, t}}\right)^{-\lambda}\left(\frac{P_{h, t}}{P_{t}}\right)^{-\omega} C_{t}\right]}{E_{t-1}\left[\tilde{D}_{t}\left(\frac{1}{P_{h, t}}\right)^{-\lambda}\left(\frac{P_{h, t}}{P_{t}}\right)^{-\omega} C_{t}\right]}, \\
P_{\text {preset }, h, t}^{*} \equiv \frac{\lambda}{\lambda-1} \frac{E_{t-1}\left[\tilde{D}_{t} \frac{W_{t}}{A_{t}}\left(\frac{1}{P_{h, t}^{*}}\right)^{-\lambda}\left(\frac{P_{h, t}^{*}}{P_{t}^{*}}\right)^{-\omega} C_{t}^{*}\right]}{E_{t-1}\left[\tilde{D}_{t}\left(\frac{1}{P_{h, t}^{*}}\right)^{-\lambda}\left(\frac{P_{h, t}^{*}}{P_{t}^{*}}\right)^{-\omega} C_{t}^{*}\right]},
\end{gathered}
$$


where $\tilde{D}$ is the stochastic discount factor, and $P_{\text {preset } h, t}$ is the optimal price for the Home market at time $t$ of the goods produced by the firms that set prices in advance. Now we can rewrite the price indexes as follows:

$$
\begin{aligned}
P_{h, t} & =\left[(1-\tau) P_{\text {flex }, h, t}^{1-\lambda}+\tau P_{\text {preset }, h, t}^{1-\lambda}\right]^{\frac{1}{1-\lambda}}, \\
P_{f, t} & =\left[(1-\tau) P_{\text {flex }, f, t}^{1-\lambda}+\tau P_{\text {preset }, f, t}^{1-\lambda}\right]^{\frac{1}{1-\lambda}} .
\end{aligned}
$$

Since we have CES sub-utility functions, the market clearing condition can be obtained by equating the output with the sum of the demands for Home goods:

$$
A_{t} L_{t}=\frac{1}{2}\left(\frac{P_{h, t}}{P_{t}}\right)^{-\omega} C_{t}+\frac{1}{2}\left(\frac{P_{h, t}^{*}}{P_{t}^{*}}\right)^{-\omega} C_{t}^{*} .
$$

While flexible-price firms will have higher profit than preset-price firms in general, CES subutility makes the aggregate profit of each country the same as before:

$$
\begin{gathered}
\Pi_{t}=\frac{1}{2} P_{h, t}\left(\frac{P_{h, t}}{P_{t}}\right)^{-\omega} C_{t}+\frac{1}{2} S_{t} P_{h, t}^{*}\left(\frac{P_{h, t}^{*}}{P_{t}^{*}}\right)^{-\omega} C_{t}^{*}-W_{t} L_{t}, \\
S_{t} \Pi_{t}^{*}=\frac{1}{2} S_{t} P_{f, t}^{*}\left(\frac{P_{f, t}^{*}}{P_{t}^{*}}\right)^{-\omega} C_{t}^{*}+\frac{1}{2} P_{f, t}\left(\frac{P_{f, t}}{P_{t}}\right)^{-\omega} C_{t}-S_{t} W_{t}^{*} L_{t}^{*} .
\end{gathered}
$$

We assume that

$$
\begin{array}{cc}
m_{t+1}=m_{t}+v_{t+1}^{m}, & m_{t+1}^{*}=m_{t}^{*}+v_{t+1}^{m^{*}}, \\
a_{t+1}^{W}=\vartheta_{W} a_{t}^{W}+v_{t+1}^{W}, & a_{t+1}^{R}=\vartheta_{R} a_{t}^{R}+v_{t+1}^{R},
\end{array}
$$

where $\vartheta_{w} \in[0,1], \vartheta_{R} \in[0,1)$ are degrees of persistence in world and relative technology levels and where $v_{t}^{x}\left(x=m, m^{*}, W, R\right)$ are i.i.d. shocks. We denote $\ln \left(X_{t}\right)$ as $x_{t}$, the world variables as $x_{t}^{W}=\frac{1}{2} x_{t}+\frac{1}{2} x_{t}^{*}$, and the relative variables as $x_{t}^{R}=x_{t}-x_{t}^{*}$. We assume $E v_{t+1}^{m}=E v_{t+1}^{m^{*}}=\frac{1}{2} \sigma_{m}^{2}$, so that $E_{t}\left(M_{t+1}^{-1}\right)=M_{t}^{-1}$ as mentioned above. We assume also $\operatorname{var}\left(v^{m}\right)=\operatorname{var}\left(v^{m^{*}}\right)=\sigma_{m}^{2}$, and $\operatorname{cov}\left(v^{m}, v^{m^{*}}\right)=\sigma_{m, m^{*}}, \operatorname{var}\left(v^{W}\right)=\sigma_{W}^{2}, \operatorname{var}\left(v^{R}\right)=\sigma_{R}^{2}$, and $\operatorname{cov}\left(v^{W}, v^{R}\right)=0$. We assume initial symmetry between Home and Foreign: that is, $a_{0}^{R}=0$, and $m_{0}^{R}=0$. Note in particular that we have not made any assumptions about the correlation of monetary shocks and productivity shocks. As long as there is some independent component to the money shocks - that is, as long as the correlation between money and productivity shocks lies on the interval $[0,1)$ - our results go through.

\subsection{Solution of the Dynamic Model}

\section{Stationarity of solution}


To solve the model, we use approximations similar to those in the static model. The Appendix presents the solution to the model. There, the equilibrium is defined and solutions for all the endogenous variables are given. It shows that the equilibrium conditions are satisfied for those solutions. The derivation of the solution is extremely algebra intensive. Here we discuss the salient features of the solution.

An important feature of the solution is that we are able to replicate the allocation achieved when a full set of state-contingent nominal bonds are traded in the linearly approximated model. We have two kinds of assets (equities and forward currency contracts) that span the space generated by $a_{t}^{R}$ and $m_{t}^{R}$. In that case, we have

$$
\rho\left(c_{t}-c_{t}^{*}\right)=s_{t}+p_{t}^{*}-p_{t} .
$$

This equation is the familiar condition that arises when there is a full set of contingent claims but in which consumer price levels are not equal (see, for example, Chari, Kehoe and Mcgrattan (2002).) Pushing the time subscripts one period forward and taking expectations at time $t$, we get

$$
E_{t}\left(c_{t+1}\right)=E_{t}\left(c_{t+1}^{*}\right) .
$$

This equation follows because prices are sticky for at most one period, so purchasing power parity holds in expectation.

Equation (3.27) demonstrates a key sort of stationarity that emerges from our dynamic solution. Even though consumption levels might differ between Home and Foreign households at any time, looking forward they are always expected to be equal. That follows because, as we show in the Appendix (where $\zeta$ is defined for the dynamic model),

$$
\zeta v_{t}^{R}+(1-\zeta) h_{t}^{R}-s_{t}=0 .
$$

This equation means that relative total wealth, which is the sum of financial wealth and human capital, is equalized between Home and Foreign households. To be clear, $V_{t}$ is defined as the value of equities that the Home household acquires at time $t$ and carries into period $t+1$, and $H_{t}$ is the expected value at time $t$ of returns to work from $t+1$ onward. So equation (3.28) says that the wealth levels of Home and Foreign households at the end of period $t$ are equal.

This equality of wealth occurs even though in equilibrium Home and Foreign households hold different equity portfolios. Since the conditionally expected return on equities depends on the realization of shocks, $v_{t}^{R} \neq 0$ in general. That is, the conditional expectations of discounted payoffs on the Home and Foreign equity portfolios differ. In addition, $h_{t}^{R} \neq 0$. The value of human capital for Home and Foreign households also depends on the realization of shocks, and so they are not in general equal.

Why then is relative total wealth equal? Suppose there is a positive relative technology shock, $a_{t}^{R}>0$, but no change in world productivity so that Home productivity rises and Foreign productivity 
falls. Hold monetary shocks equal to zero. In this case, we can show that neither Home nor Foreign consumption levels will be changed by the $a_{t}^{R}$ shock in equilibrium, which is convenient for this example.

Period $t$ wage income of Home workers falls when prices are sufficiently sticky, and period $t$ wage income of Foreign workers rises, as in the static model. The period $t$ profits of Home firms rise and period $t$ profits of Foreign firms fall. The current income of Home relative to Foreign might rise or fall. On the one hand, Home's relative labor income falls, but the profits Home households reap may be greater than that of Foreign households when there is home bias in equity holdings. Nonetheless, under the parameter configuration that delivers home bias, the overall income of Home falls relative to Foreign - the relative loss in wage income must outweigh any relative gain in profit income.

But, in this situation in which home bias arises, the relative decline in current income for Home is precisely offset by the gains Home gets in the value of its human wealth and the gain in the value of the equities that it carries into period $t$. The positive realization of $a_{t}^{R}$ pushes up $Q_{t}$ relative to $Q_{t}^{*}$ and $H_{t}$ relative to $H_{t}^{*}$. Home's total wealth - the sum of the income it receives in period $t$ from labor and profits, plus the value (after the realization of $a_{t}^{R}$ ) of the equity position it carries into period $t$, plus the value of its human wealth - is unchanged relative to Foreign. Since consumption levels are not affected by $a_{t}^{R}$ shocks, the relative wealth of Home and Foreign at the end of period $t$ is unchanged.

\section{Optimal portfolio}

We show in the Appendix that $\delta_{t}$ and $\gamma_{t}$ are constant over time and given by:

$$
\begin{gathered}
\delta \equiv \delta_{t}=\frac{1}{2}\left(\frac{1}{\rho}-1\right) \tau, \\
\gamma \equiv \gamma_{t}=\gamma_{t}^{*}=\frac{1}{2(1-\zeta)} \frac{\Lambda}{\Omega+\Lambda},
\end{gathered}
$$

where $\Lambda \equiv(1-\beta)(\psi+1)(\omega-1)\left[\frac{1-\tau}{1+\omega(1-\tau) \psi}+\frac{1}{1+\omega \psi} \frac{\beta \vartheta_{R}}{1-\beta \vartheta_{R}}\right]$ and $\Omega \equiv \frac{\zeta}{1-\zeta} \frac{(1-\beta)(\psi+1) \tau}{1+\omega(1-\tau) \psi}$. Our formula for the optimal share can be written as $\gamma=\gamma^{F L E X} \frac{\Lambda}{\Lambda+\Omega}$, where $\gamma^{F L E X}$ is the share of foreign assets in the portfolio when prices are fully flexible.

The share of the equity portfolio held in foreign assets, $\gamma$, is increasing in $\Lambda$, decreasing in $\Omega$. In order to have home bias, or $\gamma<\frac{1}{2}$, we need ${ }^{24}$

\footnotetext{
${ }^{24}$ We omit the case in which the denominator in equation (3.30) is non-positive: this case can happen only if the price is very flexible and $\omega \leq 1$.
} 


$$
\frac{1-\omega(1-\tau)}{1+\omega(1-\tau) \psi}-\frac{\omega-1}{1+\omega \psi} \frac{\beta \vartheta_{R}}{1-\beta \vartheta_{R}}>0
$$

Notice that the condition (3.31) does not depend on $\rho$ or $\zeta$, while $\zeta$ determines the level of home bias. There are intuitive explanations for how most of these parameters affect foreign equity demand.

As labor's share, $\zeta$, rises, $\gamma$ falls when there is home bias, and rises when there is antihome-bias. The intuition is straightforward given our discussion above: When the short-run effects that lead to a negative covariance of Home profits and labor income are sufficiently large that there is home bias, the home bias is amplified the larger is labor's share. The benefits from hedging labor income risk are greater when labor's share is greater. But when the long-run effects dominate, and returns to human capital are hedged by having a foreign-equity bias, the effect is again amplified the larger is labor's share.

$\beta \vartheta_{R}$ is, in a sense, a measure of the weight the future receives in the portfolio allocation decision. $\beta \vartheta_{R}$ is large when households place a high weight on the future, and when the relative productivity shocks have a very persistent influence. In the extreme case when all prices are sticky $(\tau=1)$ and the future does not matter $\left(\beta \vartheta_{R}=0\right)$, there is complete home bias $(\gamma=0$.) This actually is just the static model we examined previously - that assumed full price stickiness and placed no weight on the future.

On the other hand, if all goods prices were flexible, $\tau=0$, then the optimal equity portfolio is $\gamma=\frac{1}{2} \frac{1}{1-\zeta}>\frac{1}{2}$. This outcome is similar to the theoretical result obtained by Baxter and Jermann (1997) - "the international diversification puzzle is worse than you think.”

$\gamma$ is decreasing in $\tau$, when $\omega>1$-- increasing price stickiness leads to greater home bias in equity holdings.

When $\omega>1$, an increase in $\beta \vartheta_{R}$ leads to an increase in $\Lambda$, which implies a greater share of Foreign equities in the Home household's portfolio. In short, the more the future "matters", the larger the share of Foreign equities. In the limit, as $\beta \vartheta_{R} \rightarrow 1$, the portfolio approaches the flexible price value, $\quad \gamma=\frac{1}{2} \frac{1}{1-\zeta}$. On the other hand, as $\beta \vartheta_{R} \rightarrow 0$, the portfolio approaches $\gamma=\frac{1}{2} \frac{(\omega-1)(1-\tau)}{\tau \zeta+(1-\zeta)(\omega-1)(1-\tau)}$. This latter value is precisely the level $\gamma$ would take in the static model if a fraction $\tau$ of prices were preset.

The values of home and foreign equities are determined by the expected present discounted value of current and future profits of the firms. Would we not expect that the long run effects of productivity growth on dividend growth and labor income growth wash out any temporary effects from price stickiness? Why would temporarily sticky prices matter so much? 
The answer is that when goods prices adjust, terms of trade movements play an independent role in hedging consumption risk for households. When the home country, for example, has a negative productivity shock, its export price rises because the supply of its good has diminished. The increase in the relative price of its import tends to soften the blow from the negative productivity outcome. Indeed, as Cole and Obstfeld (1991) point out, when the elasticity of substitution between home and foreign goods is unity ( $\omega=1$ ), the terms of trade movements provide complete consumption insurance without the need for any asset trade. ${ }^{25}$

The implication for portfolio choice is that the gains in households' utility from diversifying their equity portfolios are reduced by the terms-of-trade effect. So, while the optimal portfolio under flexible prices exhibits bias toward foreign equities, deviations from the optimal allocation may not impose much utility cost (and the cost goes to zero as $\omega$ goes to one.) But this insurance from terms of trade is not present when nominal prices are sticky. Productivity shocks cannot change pre-set goods prices, and the exchange rate is determined in equilibrium by monetary shocks. The equity portfolio must provide the hedge against productivity shocks when prices are sticky. As the elasticity of substitution, $\omega$, approaches unity, this effect will dominate any gains from hedging longer run risks.

In our model, a fraction $\tau$ of the firms have set the price in advance for a single period. The response of the cash flow of those firms to a relative productivity shock, $\hat{a}_{t}^{R}$, is given by $\Omega$, defined above.

In the period that a shock occurs, a fraction $1-\tau$ firms adjust their price freely. The impact of a relative productivity shock on their cash flow is given by $(1-\beta)(\psi+1) \frac{(1-\tau)(\omega-1)}{1+\omega(1-\tau) \psi}$. The period after the shock, all firms adjust their prices. The expected discounted impact on cash flow from a relative productivity shock is given by $(1-\beta)(\psi+1) \frac{\omega-1}{1+\omega \psi} \frac{\beta \vartheta_{R}}{1-\beta \vartheta_{R}}$. Adding the initial-period effect to the long-run effect, we get the total effect of a one-unit change in $\hat{a}_{t}^{R}$ on the expected discounted cash-flow of firms that are adjusting their goods price to be $\Lambda$, defined above.

In these expressions, to be clear, the cash flow to sticky price firms refers to the one period during which the measure $\tau$ firms have set prices in advance. After the period in which the shocks occur, all firms are flexible-price firms. Nonetheless, the response of cash flow among sticky price firms can be much larger than the discounted sum of cash flow to flexible-price firms. For simplicity, if all firms were initially sticky price ( $\tau=1$ ), we see from these expressions that the impact of $\hat{a}_{t}^{R}$ on the sticky-price firms' initial cash flow is given by $(1-\beta)(\psi+1) \frac{\zeta}{1-\zeta}$. But the impact on the present

25 Heathcote and Perri (2004) assume $\omega=1$, but assume that there is investment in capital and trade only in equities, and find that home bias can arise even with flexible goods prices. 
discounted value of cash flow after the period of the shock is given by $(1-\beta)(\psi+1) \frac{\omega-1}{1+\omega \psi} \frac{\beta \vartheta_{R}}{1-\beta \vartheta_{R}}$. Although the latter cash flow is enlarged because it represents the cash flow over an infinite horizon, and so is multiplied by $\frac{\beta \vartheta_{R}}{1-\beta \vartheta_{R}}$, there are two other factors that work to make the effect on the cash flow after the initial period small relative to the initial-period effect. First, under flexible prices the terms of trade changes dampen the effects of productivity shocks on firm revenues. That channel does not exist in the initial period under sticky prices. So, $\frac{\omega-1}{1+\omega \psi}$ multiplies the cash flow in $\Lambda$, but not in $\Omega$. This works to reduce the effect of relative productivity shocks on $\Lambda .{ }^{26}$ Second, in the initial period, firms do not "share" the benefit of the productivity increase with workers, so the initial effect when prices are sticky is multiplied by $\zeta /(1-\zeta)$.

Formally, we can evaluate the effect of increasing price stickiness on the optimal portfolio, $\gamma$, starting from a situation in which all goods prices are flexible $(\tau=0)$. We find:

$$
\left.\frac{\partial \gamma}{\partial \tau}\right|_{\tau=0}=-\frac{1}{2} \frac{\zeta}{(1-\zeta)^{2}} \frac{1-\beta \vartheta_{R}}{\omega-1}
$$

The limit of this derivative as $\omega$ approaches unity from above is negative infinity . More generally, if the elasticity of substitution between home and foreign goods is not too different than one, a small amount of price stickiness can have a large effect on the portfolio. In the next section, we use values of the parameters of this model from calibrated general equilibrium models in the literature and find that the amount of home bias implied by the model is considerable.

\subsection{Properties of the Model}

We can calibrate the amount of home bias implied by the model. Although the model is not realistic enough to capture some features of the macroeconomy, it is still worthwhile to get a sense of the magnitude of home bias implied by the solution in equation (3.31). The share of the Home household's equity portfolio held in foreign shares, $\gamma$, depends on the price stickiness parameter, $\tau$; labor's share, $\zeta$; the elasticity of substitution between Home and Foreign aggregates, $\omega$; the discount factor, $\beta$; the persistence of relative productivity shocks, $\vartheta_{R}$; and, the elasticity of labor supply, $\psi$.

In most calibrations of new-Keynesian models with nominal price stickiness, the expected life of a nominal price (under Calvo price setting) is calibrated to be four quarters. ${ }^{27}$ However, evidence produced by Bils and Klenow (2004) suggests that the average life of a price is closer to two quarters. We will consider both calibrations. In our model, a measure $\tau$ of firms set prices for one period, and

\footnotetext{
${ }^{26}$ This could increase the effect of relative productivity shocks on $F L$ in the empirically implausible case that $\psi<1$ and $\omega>2 /(1-\psi)$.

27 Taylor (1999) is usually cited as a source for this calibration. See for example Huang and Liu (2005),
} 
a measure $1-\tau$ adjust prices instantaneously. So the expected life of a price is $\tau$ periods. We set $\tau=0.8$, on the grounds that perhaps $20 \%$ of firms adjust prices freely. These firms produce "raw products" in the terminology of Bils and Klenow - fresh foods, gasoline, etc. The share of these firms is certainly less than $20 \%$ using Bils and Klenows' classification. But we choose a higher value because it biases the results against being able to explain home bias. That is, given the average life of prices, the more flexible price firms (the smaller is $\tau$ ), the more home bias. With $\tau=0.8$, a period is equal to five quarters if the average life of a price is 4 quarters, and is equal to 2.5 quarters if the average lifespan of a price is two quarters.

Following Backus, Kehoe and Kydland (1992), we set $\zeta=2 / 3$. The estimates of Backus, Kehoe and Kydland (1992) give us on quarterly data that the autocorrelation of relative productivity shocks is 0.855 , so we set $\vartheta_{R}=(0.855)^{5} \approx 0.457$ using the standard calibration for price adjustment, or $\vartheta_{R}=(0.855)^{2.5} \approx 0.676$ if the period of price adjustment is shorter. Likewise, the quarterly discount factor in Backus et al. is 0.99 , so we take $\beta=(0.99)^{5} \approx 0.951$ or $\beta=(0.99)^{2.5} \approx 0.975$. We follow Backus, Kehoe and Kydland (1994), and Chari, Kehoe and Mcgrattan (2002) and set $\omega=1.5$. We follow Obstfeld and Rogoff (2002), and Bergin (2004) and set $\psi=1$.

With these parameters, we find $\gamma \approx 0.24$, or $\gamma \approx 0.41$ when we assume speedier price adjustment. The model is symmetric between Home and Foreign countries, so an unbiased portfolio would be $\gamma=0.5$. Under the standard calibration of price stickiness, the model predicts substantial home bias. Even with the assumption of more rapid price adjustment - expected life of a price equal to two quarters - we find home bias in equities. This finding should be compared to the prediction of the flexible-price model, which has strong anti-home bias of Baxter and Jermann (1997) with $\gamma^{\text {FLEX }}=1.5$. Just a small amount of price stickiness substantially changes the optimal portfolio, moving it in the direction of holding a greater share of home equities.

The ratio of the sticky-price portfolio share to the flexible-price portfolio share of foreign equities, $\gamma / \gamma^{\text {FLEX }}$ depends on the elasticity of substitution, $\omega$, as we have emphasized. When we use the standard parametrization of $\omega=1.5, \gamma / \gamma^{F L E X}$ is equal to 0.16 when the average life of a price is 4 quarters, and 0.27 when the average life is 2 quarters. The corresponding ratios when $\omega=3$ are 0.39 and 0.55. As $\omega$ increases, $\gamma / \gamma^{\text {FEX }}$ rises, but it remains less than one - price stickiness reduces home bias.

We now examine some other dimensions of our model. In our model, negative conditional correlation between labor hours and productivity conditioning on productivity shock is the key driving force for home bias. However, because households can hedge demand shock through forward contracts, the unconditional correlation can be positive. It is important to distinguish between conditional and unconditional correlation in our model. 
Gali (1999) has noted that real business cycle models tend to imply a positive correlation between hours and productivity. He shows in a simple closed-economy New Keynesian macroeconomic model that there is a negative correlation between hours and output per worker when there is a productivity shock. The reasoning is much the same as that in our model.

Gali goes on to derive empirical support for this implication of sticky-price models. He estimates a structural bivariate VAR on total labor hours and labor productivity using U.S. data. ${ }^{28}$ The model was estimated on quarterly data from 1948:I to 1994:IV. There are two types of shocks in the model, which Gali classifies as technology shocks and non-technology shocks. The nontechnology shocks can be associated with aggregate demand shocks. Under his identification scheme, only technology shocks can permanently increase labor productivity.

Gali finds that the conditional correlation between labor hours and productivity is negative for technology shocks, while the unconditional correlation is positive. Rotemberg (2003) finds similar results. If prices were flexible, in traditional real business cycle models, the correlation conditional on technology shocks would be positive - as it is in our model in the long run.

Gali's findings have not gone unchallenged. ${ }^{29}$ Christiano, Eichenbum and Vigfusson (2003) substitute labor hours per capita for Gali's total labor hours and reverse Gali's finding on the conditional correlation. However, Francis and Ramey (2005a) use the same measure, but quadratically detrended, and find the negative correlation between hours per capita and productivity conditional on technology shocks. Gali, Lopez-Salido and Valles (2003) find a similar result, using first-differences in hours per capita. Francis and Ramey (2005b) create a new measure of hours per capita and confirm that a positive technology shock will reduce labor hours in the short run. While there is no consensus yet on the sign of the conditional correlation, there is some significant empirical support for the contention that it is negative.

Home bias does not require that the unconditional correlation of returns to human capital and returns to domestic equity be positive for two reasons: First, as we note above, productivity shocks may have a low variance relative to monetary shocks, but it is the covariance holding monetary shocks constant that matters for home bias. Second, it is the correlation of returns to human capital with the relative Home to Foreign equity returns that matters for productivity. If Home and Foreign productivity shocks are highly correlated, there may be home bias even when the conditional correlation of human capital returns and domestic equity returns is high. This is illustrated in Tables 2 and 3. Here, we use the parameter values from our two experiments above in which the average life of a price was 4 quarters and 2 quarters. In addition, we set the coefficient of relative risk aversion, $\rho$, equal to two, and we assume the world productivity shock is permanent, $\vartheta_{w}=1.0$.

\footnotetext{
${ }^{28}$ He also uses employment instead of labor hours, and finds the same result holds for all G7 countries except Japan.

${ }^{29}$ See Gali and Rabanal (2005) for details.
} 
Table 2 presents the correlation of returns on human capital with returns to domestic equities. The correlation is calculated under alternative assumptions about the correlation of innovations to home and foreign productivity, and alternative assumptions about the standard deviation of productivity innovations relative to money supply innovations. There is a positive correlation of returns to human capital and Home equities in all cases. The correlations reported in this table (and Table 3) are under the assumption that home and foreign monetary innovations are uncorrelated, but we find that the return correlations are virtually unchanged if we raise the money correlations to 0.5 .

Table 3 presents the correlation of returns on human capital with returns to domestic equities relative to foreign equities. Even here, we see that the correlations are positive unless the variance of productivity shocks is quite large relative to the variance of monetary shocks. What is a reasonable value for these relative variances? Gali and Rabanal (2004) provide one measure. They estimate a simple VAR using US data on hours and output in the non-farm sector. According to their measure, the ratio of the standard deviation of the home productivity shock to the home monetary shock is 1.12. ${ }^{30}$ We see from table 3 that when the standard deviations of the two shocks are approximately equal, the model implies a positive correlation between the returns to human capital and the return to domestic equities relative to foreign equities.

Table 4 reports some other correlations implied by the model. Table 4a refers to the case of average price duration of 4 quarters, and Table $4 \mathrm{~b}$ to the case of 2-quarter duration. The top panel in each table reports the correlation of changes in logs of home and foreign consumption, the second panel is the correlation of changes in logs of home and foreign output, and the third is the correlation of changes in home consumption and output. These correlations are reported under various assumptions about the correlation of innovations in productivity shocks and the standard deviation of productivity shocks relative to monetary shocks (as in Tables 2 and 3).

Backus, Kydland, and Kehoe (1992) report for example that the correlation of US and European consumption is 0.46 and output is 0.70 . They report a correlation of US consumption with US output of 0.76. (All of these are using Hodrick-Prescott detrending.) The numbers that we report in Table 4 are roughly in this range. For example in Table 4a, when we assume equal volatility of productivity and monetary innovations (as Gali and Rabanal find), and when home and foreign productivity innovations have a correlation of 0.75 , then we find the correlation of home and foreign consumption growth is 0.39 , the correlation of home and foreign output growth is 0.80 , and the correlation of home consumption and output growth is 0.79 . When prices are assumed to be sticky for a shorter period of time (Table 4b), the corresponding correlations are 0.39 for home-foreign consumption growth, 0.72 for home-foreign output growth, and 0.78 for home consumption-output growth. $^{31}$

\footnotetext{
30 These variances are not reported in the paper, but were kindly provided to us by Pau Rabanal.

${ }^{31}$ Note that in Backus, Kydland, and Kehoe, the reported correlation of shocks is closer to 0.25, rather than 0.75. All of the correlations are a bit lower in that case. However, we should not rely on BKK's estimate of this
} 
In both the static and dynamic models, the allocation in the linearly approximated model replicates the one achieved when a full set of state-contingent bonds is traded. This is in a sense a shortcoming of our model since this allocation leaves other puzzles unsolved - the high volatility of the observed exchange rate or the consumption-real exchange rate anomaly as described in Chari et al. (2002).

One possible way of extending our model may help to explain the anomalous behavior of real exchange rates and consumption, while maintaining our mechanism for home bias. Julliard (2004) argues, in a partial-equilibrium setting, that credit constraints (specifically, a constraint that prevents short selling of equities or bonds), may lead to substantial home bias when returns to human capital and relative equity returns are negatively correlated. His argument is that unconstrained households would prefer a portfolio weighted toward home equities for reasons similar to the ones discussed in this paper (though he takes as given the source of this negative correlation, rather than deriving it from a model.) Credit constrained households would like to go short in some assets. During the lifecycle of these households, they may move to a position in which they hold positive amounts of equities. Julliard demonstrates that these households that are just emerging from the credit constraint have a strong incentive to diversify their labor income risk, which they would do by acquiring a portfolio that is strongly biased toward domestic equities.

If such a model were to be embedded into a general equilibrium framework, the very tight link between the real exchange rate and relative consumption levels implied by our model would be broken. However, such a model would be very much more difficult to solve (even numerically) and it is unlikely that one could obtain a closed-form solution for the foreign equity share such as our equation (3.30).

Finally, our model implies that home bias arises because domestic equities provide a hedge for labor income. There is some evidence that bears out this source of home bias. Our evidence comes from the Survey of Consumer Finances 2001 public data, reported by the Federal Reserve Board. In Table 5 we report the results of regressions of a household's equity share in their portfolio on the share of their income derived from labor income. To measure labor's share, we simply divide income reported from wages and salaries by the sum of income from all sources. We eliminate observations that do not lie between zero and one. Table 5 reports results for three different measures of the dependent variable. The first uses the value of foreign stocks directly held by households divided by the value of all stocks held by households. The second takes the value of foreign stocks divided by equity held by households (which is the sum of stocks, stock portfolio mutual funds and $50 \%$ of mixed portfolio mutual funds held by households.) The third takes the value of stocks divided by the total financial wealth held by households. In all cases, we report a negative coefficient on

correlation because it comes from a model in which output is driven only from technology shocks. Further empirical investigation of our model is required. 
labor income, as our model predicts: as labor income increases as a share of household income, home bias increases. In the second and third regression, the coefficient is significant at the 5 percent level.

\section{Conclusion}

Our model provides a general equilibrium analysis of the factors that determine equilibrium portfolio choice in a dynamic setting. Sticky-price portfolio balance models have been a staple of open-economy macroeconomics for decades, but until now there was no fully integrated dynamic stochastic equilibrium model. Our model is, we believe, a starting point. We are able to solve the model in closed form, and therefore we can provide some novel insights into the interplay between financial markets and the macroeconomy.

We have stressed a few of these features. First, we have demonstrated that even a small amount of nominal rigidity - price setting with a relatively short duration - can dramatically alter equilibrium equity portfolios. Second, our model shows clearly how the different roles of monetary shocks and productivity shocks in determining equity portfolios and bond portfolios (or the position in the market for forward foreign exchange.) And, our model provides an interesting new mechanism that may help explain some of the home bias in equity portfolios.

Although our model provides a theoretical foundation for home bias, we believe other factors, such as information costs, play important roles. The economic forces that lead to home bias in our model do not require the exclusion of other considerations that have been raised in the literature. We have not built a model that is intended to explain home bias, because it does not include any features that are designed explicitly to deliver home bias. Instead, we have found that home bias is a natural outcome in a symmetric model in which output is demand determined to some extent and claims to labor income are not traded. The model can be solved analytically in a straightforward way, and extensions of this framework may prove useful in examining other questions in international finance, such as the role of valuation effects in external adjustment; the effects of portfolio adjustment on macroeconomic and current account adjustment, the relationship between movements in stock prices and exchange rates, etc. 


\section{References}

Aizenman, Joshua. 1999. "International Portfolio Diversification with Generalized Expected Utility Preferences.” Canadian Journal of Economics, 32 (4), 995-1008.

Backus, David K.; Patrick J. Kehoe; and, Finn E. Kydland. 1992. "International Real Business Cycles.” Journal of Political Economy, 100 (4), 745-75. , and 1994. "Dynamics of the Trade Balance and the Terms of Trade: The J-Curve?” American Economic Review, 84 (1), 84-103.

Baxter, Marianne, and Mario Crucini. 1995. "Business Cycles and the Asset Structure of Foreign Trade.” International Economic Review, 36 (4), 821-854.

and Urban J. Jermann. 1997. "The International Diversification Puzzle Is Worse Than You Think.” American Economic Review, 87 (1), 170-80. , and Robert G. King. 1998. "Nontraded Goods, Nontraded Factors, and International NonDiversification.” Journal of International Economics, 44 (2), 211-229.

Bergin, Paul R. 2004. "How Well Can the New Open Economy Macroeconomics Explain the Exchange Rate and the Current Account?” National Bureau of Economic Research, working paper no. 10356.

Black, Stanley. 1973. "International Money Markets and Flexible Exchange Rates,” Princeton Studies in International Finance, no. 25.

Blanchard, Olivier Jean and Nobuhiro Kiyotaki. 1987. "Monopolistic Competition and the Effects of Aggregate Demand.” American Economic Review, 77 (4), 647-666.

; Francesco Giavazzi; and, Filipa Sa. 2005. "The U.S. Current Account and the Dollar.” National Bureau of Economic Research, working paper no. 11137.

Bottazzi, Laura; Paolo Pesenti; and, Eric van Wincoop. 1996. "Wages, Profits and the International Portfolio Puzzle.” European Economic Review, 40 (2), 219-254.

Branson, William H. 1977. "Asset Prices and Relative Prices in Exchange Rate Determination.” Sozialwissenschaftliche Annalen, 1, 69-89.

Branson, William H., and Dale W. Henderson. 1985. "The Specification and Influence of Asset Markets.” In Ronald W. Jones and Peter B. Kenen, eds., Handbook of International Economics, vol. 2 (Amsterdam: Elsevier), 749-805.

Butler, Kirt C., and Domingo C. Joaquin. 2002. "Are the Gains from International Portfolio Diversification Exaggerated? The Influence of Downside Risk in Bear Markets.” Journal of International Money and Finance, 21 (7), 981-1011.

Chari, V. V.; Patrick J. Kehoe; and, Ellen R. McGrattan. 2002. "Can Sticky Price Models Generate Volatile and Persistent Real Exchange Rates?” Review of Economic Studies, 69 (3), 533-563.

Christiano, Lawrence J.; Martin Eichenbaum; and, Robert Vigfusson. 2003. "What Happens after a Technology Shock?” Board of Governors of the Federal Reserve, International Finance Discussion Papers 768.

Cole, Harold L., and Maurice Obstfeld. 1991. "Commodity Trade and International Risksharing: How Much Do Financial Markets Matter?” Journal of Monetary Economics, 28 (1), 3-24.

Dornbusch, Rudiger. 1983. "Exchange Risk and the Macroeconomics of Exchange Rate Determination.” In R.G. Hawkins, R.M. Levich., and C. Wihlborg, eds., The Internationalization of Financial Markets and National Economic Policy (Greenwich: JAI Press).

Dotsey, Michael. 2002. "Structure from Shocks." Federal Reserve Bank of Richmond Economic Quarterly, 88 (4). 
Edwards, Sebastian. 2005. "Is the U.S. Current Account Sustainable? If Not, How Costly is Adjustment Likely to Be?” Brookings Papers on Economic Activity (1), 211-271.

Eldor, Rafael; David Pines; and, Abba Schwarz. 1988. "Home Asset Preference and Productivity Shocks.” Journal of International Economics, 25 (1/2), 165-176.

Francis, Neville, and Valerie A. Ramey. 2005a. "Is the Technology-Driven Real Business Cycle Hypothesis Dead? Shocks and Aggregate Fluctuations Revisited." Journal of Monetary Economics 52 (8), 1379-1399.

and __. 2005b. "Measures of Per Capita Hours and Their Implications for the Technology-Hours Debate.” National Bureau of Economic Research, working paper no. 11694.

French, Kenneth R., and James M. Poterba. 1991. "Investor Diversification and International Equity Markets.” American Economic Review, 81 (2), 222-226.

Gali, Jordi. 1999. "Technology, Employment, and the Business Cycle: Do Technology Shocks Explain Aggregate Fluctuations?” American Economic Review, 89 (1), 249-271.

and Pau Rabanal. 2005. "Technology Shocks and Aggregate Fluctuations: How Well Does the RBC Model Fit Postwar U.S. Data?” In Mark Gertler and Kenneth Rogoff, eds., NBER Macroeconomics Annual, 2004 (Cambridge: MIT Press).

J. David Lopez-Salido, and Javier Valles. 2003. "Technology Shocks and Monetary Policy: Assessing the Fed's Performance.” Journal of Monetary Economics, 50 (4), 723-743.

Gourinchas, Pierre-Olivier, and Helene Rey 2005. "International Financial Adjustment.” National Bureau of Economic Research, working paper no. 11155.

Hasan, Iftekhar, and Yusif Simaan. 2000. “A Rational Explanation for Home Country Bias.” Journal of International Money and Finance, 19 (3), 331-631.

Hau, Harald, and Helene Rey. 2006. “Exchange Rates, Equity Prices, and Capital Flows.” Review of Financial Studies, 19(1), 273-317.

Heathcote, Jonathan, and Fabrizio Perri. 2004. "The International Diversification Puzzle is Not as Bad as You Think.” New York University, manuscript.

Huang, Kevin X. D., and Zheng Liu. 2005. “Inflation Targeting: What Inflation Rate to Target?” Journal of Monetary Economics, 52 (8), 1435-1462.

Jermann, Urban J. 2002. "International Portfolio Diversification and Endogenous Labor Supply Choice.” European Economic Review, 46 (3), 507-522.

Julliard, Christian. 2004. "Human Capital and International Portfolio Choice.” Princeton University, manuscript.

Kang, Jun Koo, and Rene M. Stulz. 1997. "Why Is There a Home Bias? An Analysis of Foreign Portfolio Equity Ownership in Japan.” Journal of Financial Economics, 46 (1), 3-28.

Kehoe, Patrick, and Fabrizio Perri. 2002. "International Business Cycles with Incomplete Markets.” Econometrica, 70 (3), 907-928.

Lewis, Karen K. 1999. “Trying to Explain Home Bias in Equities and Consumption.” Journal of Economic Literature, 37 (2), 571-608.

2000. "Why Do Stocks and Consumption Imply Such Different Gains from International Risk Sharing?” Journal of International Economics, 52 (1), 1-35.

Lucas, Robert J. 1982. "Interest Rates and Currency Prices in a Two-Country World," Journal of Monetary Economics, 10 (3), 335-359.

Matsumoto, Akito. 2004. "Essays in International Finance." University of Wisconsin, Ph.D. dissertation. 
Obstfeld, Maurice. 2004. "Bernard Harms Lecture: External Adjustment." Review of World Economics 140 (4): 541-568.

Obstfeld, Maurice, and Kenneth Rogoff. 1996. Foundations of International Macroeconomics, (Cambridge: MIT Press).

and __ . 2001. "The Six Major Puzzles in International Macroeconomics: Is There a Common Cause?” In Ben S. Bernanke and Kenneth Rogoff, eds., NBER Macroeconomics Annual, 2000, (Cambridge: MIT Press).

and __. 2002. "Risk and Exchange Rates.” In Elhanan Helpman and Effraim Sadka, eds., Contemporary Economic Policy: Essays in Honor of Assaf Razin, (Cambridge: Cambridge University Press).

Palacios-Huerta, Ignacio. 2001. "The Human Capital of Stockholders and the International Diversification Puzzle.” Journal of International Economics, 54 (2), 309-331.

Pastor, Lubos. 2000. "Portfolio Selection and Asset Pricing Models.” Journal of Finance, 55 (1), 179223.

Pavlova, Anna, and Roberto Rigobon. 2003. “Asset Prices and Exchange Rates.” National Bureau of Economic Research, working paper no. 9834.

Pesenti, Paolo, and Eric van Wincoop. 2002. “Can Nontradables Generate Substantial Home Bias?” Journal of Money, Credit, and Banking, 34 (1), 25-50.

Rogoff, Kenneth. 1996. “The Purchasing Power Parity Puzzle.” Journal of Economic Literature, 34 (2), 647-668.

Rotemberg, Julio J. 2003. "Stochastic Technical Progress, Smooth Trends and Nearly Distinct Business Cycles?” American Economics Review, 93 (5), 1543-1559.

Rowland, Patrick F., and Linda L. Tesar. 2004. "Multinationals and the Gains from International Diversification.” Review of Economic Dynamics, 7 (4), 789-826.

Serrat, Angel. 2001. "A Dynamic Equilibrium Model of International Portfolio Holdings.” Econometrica, 69 (6), 1467-1489.

Stockman, Alan C., and Harris Dellas. 1989. "International Portfolio Nondiversification and Exchange Rate Variability.” Journal of International Economics, 26 (3/4), 271-289.

Taylor, John B. 1999. “Staggered Price and Wage Setting in Macroeconomics.” In John B. Taylor and Michael Woodford, eds., Handbook of Macroeconomics, vol. 1 (Amsterdam: Elsevier).

Tesar, Linda L. 1993. “International Risk-Sharing and Nontraded Goods.” Journal of International Economics, 35 (1/2), 69-89.

1995. "Evaluating the Gains from International Risksharing." Carnegie-Rochester Conference Series on Public Policy, 42, 95-143.

and Ingrid M. Werner. 1995. "Home Bias and High Turnover.” Journal of International Money and Finance, 14 (4), 467-492.

Tille, Cedric. 2004. "Financial Integration and the Wealth Effect of Exchange Rate Fluctuations." Federal Reserve Bank of New York, manuscript.

van Nieuwerburgh, Stijn, and Laura Veldkamp. 2005. "Information Immobility and the Home Bias Puzzle.” New York University, manuscript.

van Wincoop, Eric. 1994. "Welfare Gains from International Risksharing.” Journal of Monetary Economics, 34 (2), 175-200.

1999. "How Big Are Potential Welfare Gains from International Risksharing.” Journal of International Economics, 47 (1), 109-135. 
Warnock, Francis E. 2002. "Home Bias and High Turnover Reconsidered.” Journal of International Money and Finance, 21 (6), 795-805. 


\section{Appendix}

\section{A. Solution of the Dynamic Model}

An equilibrium satisfies the first order conditions, budget constraint and market clearing conditions. First we define an equilibrium formally. Then we will list the linearized first order conditions and redefine equilibrium in linearized form.

Definition A

An equilibrium is a set of sequences ${ }^{32}\left\{C_{t}, L_{t}, W_{t}, \tilde{\delta}_{t}, \gamma_{t}, C_{h . t}, C_{f . t}, C_{h . t}(i), C_{f . t}(i), P_{f l e x, h, t}\right.$, $\left.P_{\text {flex,f,t }}, P_{\text {preset }, h, t}, P_{\text {preset }, h, t}, P_{t}, P_{h, t}, P_{f, t}, Q_{t}, V_{t}, H_{t}, R_{t}, R_{t}^{H}, \Pi_{t}, \gamma_{h, t}, \gamma_{f, t}\right\}_{t=1}^{\infty}$ and their foreign counterparts and $\left\{S_{t}, F_{t}\right\}$, which solves the system of 50 equations ${ }^{33}$ consisting of (2.5), (2.8), (2.9), (3.3), (3.4), (3.7)(3.22), and their foreign counterparts plus 3 asset markets clearing conditions, ${ }^{34}$ given stochastic sequences $\left\{A_{t}, A_{t}^{*}, M_{t}, M_{t}^{*}\right\}$ and initial conditions $A_{0}=A_{0}^{*}, M_{0}=M_{0}^{*}, \gamma_{0}=0$, and $\gamma_{0}^{*}=0$.

\section{A.1 Approximated System}

In this section, we derive a log-linear version of the model, under the assumption that the stochastic driving variables (productivity and money) are lognormally distributed. Many of the equations of the model are linear in logs (without any approximation). But some of the equations in the model (the budget constraint for households, the definition of profits for the firms, and the market clearing conditions) are log-linearized around unconditional means. It is immediately apparent that our assumptions of stationary productivity processes and unit-root monetary processes imply that nominal variables have unit roots and real variables are stationary. So we log-linearize around the unconditional means of real variables. ${ }^{35}$

In some of the log-linearized equations below, the algebra is simplified considerably if we use the result that $\overline{p_{h}-p}=0$. (In our notation, $\bar{x}$ represents the unconditional mean of $x_{t}$.) While we could proceed with the derivations without using this result, and then verify in the solutions that this result is true, it is easier to demonstrate this first and use it in some of the log-linearizations.

First, in the definition of profits for the home firm, divide both sides of equation (3.22) by $P_{t}$, then evaluate the equation at the point of expansion for the log-linearziation:

$$
\exp (\overline{\pi-p})=\exp (\bar{c})\left[\frac{1}{2} \exp \left((1-\omega)\left(\overline{p_{h}-p}\right)\right)+\frac{1}{2} \exp \left((1-\omega)\left(\overline{p_{h}^{*}-p^{*}}\right)\right)\right]-\exp (\overline{w-p}+\bar{l}) .
$$

\footnotetext{
${ }^{32}$ There are $24 \times 2+2$ variables.

${ }^{33}$ The number of equations should be 51 , but one is redundant by Walras' Law.

${ }^{34} \gamma_{h, t}+\gamma_{h, t}^{*}=1, \gamma_{f, t}+\gamma_{f, t}^{*}=1$, and $F_{t} \tilde{\delta}_{t}=\tilde{\delta}_{t}^{*}$.

${ }^{35}$ We could easily accommodate unit-root processes in productivity. Then real variables expressed in

"efficiency units" would be stationary. However, there is no real gain from this generalization, so we maintain stationary productivity shocks to simplify the algebra.
} 
Here we have used symmetry to give us $\bar{c}=\overline{c^{*}}$ and $\overline{s+p^{*}-p}=0$.

Divide the budget constraint (3.1) by $P_{t}$, then evaluate the equation at the point of expansion for the log-linearization:

$$
\exp (\overline{\pi-p})=\exp (\bar{c})-\exp (\overline{w-p}+\bar{l}) .
$$

In deriving this expression, we have used symmetry to give us $\overline{s+q^{*}-q}=0, \overline{s+\pi^{*}-\pi}=0$, and $\overline{s-f}=0$. We have also used $\gamma_{f, t}+\gamma_{h, t}=1$ and $M_{t}=M_{t-1}+T r_{t}$.

Now comparing the two equations we have derived, we must have

$$
\frac{1}{2} \exp \left((1-\omega)\left(\overline{p_{h}-p}\right)\right)+\frac{1}{2} \exp \left((1-\omega)\left(\overline{p_{h}^{*}-p^{*}}\right)\right)=1 .
$$

This can be written as

$$
\frac{1}{2} \exp \left((1-\omega)\left(\overline{p_{h}-p}\right)\right)+\frac{1}{2} \exp \left(-(1-\omega)\left(\overline{p_{h}-p}\right)\right)=1,
$$

where we have used symmetry to give us that $\overline{p_{h}^{*}-p^{*}}=\overline{p_{f}-p}$, and linearized (2.5) to get $\overline{p_{h}-p}=-\left(\overline{p_{f}-p}\right)$. It then follows that $\overline{p_{h}-p}=0$, which is the result we will use below to simplify some of the log-linearizations.

A few more notational conventions: We denote $\hat{x}_{t}$ as the deviation from the conditional mean-that is, $\hat{x}_{t} \equiv x_{t}-E_{t-1} x_{t}$ and $\hat{E} x_{t+s}=E_{t} \ln x_{t+s}-E_{t-1} \ln x_{t+s}$. We will also denote the world variables as $x_{t}^{w} \equiv \frac{1}{2} x_{t}+\frac{1}{2} x_{t}^{*}$ and the relative variables as $x_{t}^{R} \equiv x_{t}-x_{t}^{*}$.

\section{A.1.1 The first order conditions for households}

Suppressing constant terms and taking logs, the first order condition for consumption (3.14) can be written as

$$
c_{t}=\frac{1}{\rho}\left(m_{t}-p_{t}\right)
$$

Using equation (A.1), equation (3.3) can be expressed as

$$
\psi l_{t}=-m_{t}+w_{t} .
$$

Some of the equations of the model are log-linear (such as (A.1) and (A.2)), and therefore, in the presence of lognormal distributions, offer exact solutions. But others (such as the budget constraint, the market clearing condition, and the expression for a firm's profits) require approximations. Because all shocks are lognormal, the solution of the approximated model will take on a lognormal distribution. We can use equation (3.14) to express (3.4) as

$$
E_{t-1}\left(s_{t}\right)+\frac{1}{2} \operatorname{var}_{t-1}\left(s_{t}\right)-\operatorname{cov}_{t-1}\left(m_{t}, s_{t}\right)=f_{t},
$$




$$
\begin{gathered}
E_{t-1}\left(r_{t}-\left(m_{t}-m_{t-1}\right)\right)-\operatorname{cov}_{t-1}\left(m_{t}, r_{t}\right)+\frac{1}{2} \operatorname{var}_{t-1}\left(r_{t}\right)+\frac{1}{2} \operatorname{var}_{t-1}\left(m_{t}\right)=0 \\
E_{t-1}\left(r_{t}^{*}+s_{t}-s_{t-1}-\left(m_{t}-m_{t-1}\right)\right)+\frac{1}{2} \operatorname{var}_{t-1}\left(r_{t}^{*}\right)+\frac{1}{2} \operatorname{var}_{t-1}\left(m_{t}\right)+\frac{1}{2} \operatorname{var}_{t-1}\left(s_{t}\right) \\
-\operatorname{cov}_{t-1}\left(m_{t}, r_{t}^{*}\right)+\operatorname{cov}_{t-1}\left(s_{t}, r_{t}^{*}\right)-\operatorname{cov}_{t-1}\left(m_{t}, s_{t}\right)=0
\end{gathered}
$$

\section{A.1.2 The budget constraint}

We log-linearize the budget constraint (3.13) to get

$$
\begin{aligned}
& p_{t}+c_{t}+\frac{\beta}{1-\beta}(1-\zeta) v_{t}+\frac{\beta}{1-\beta} \zeta h_{t} \\
& =\frac{1}{1-\beta}(1-\zeta)\left[v_{t-1}+r_{t}-\gamma_{t}\left(r_{t}^{R}-\hat{s}_{t}\right)\right]+\frac{1}{1-\beta} \zeta\left(h_{t-1}+r_{t}^{H}\right)+\delta_{t}\left(s_{t}-f_{t}\right)
\end{aligned}
$$

Here, $\zeta \equiv \frac{\exp (\overline{w-p}+\bar{l})}{\exp (\bar{c})}$, and $\delta_{t} \equiv \frac{\tilde{\delta}_{t} F_{t}}{M_{t-1}} \exp (\overline{m-p}-\bar{c})$. In deriving this expression, we have used the fact that by symmetry, $\overline{v-p}=\overline{q-p}$, and then use equation (3.7) to derive $\exp (\overline{q-p})=\frac{\beta}{1-\beta} \exp (\overline{\pi-p})$. Similarly, from equation (3.9), we get $\exp (\overline{h-p})=\frac{\beta}{1-\beta} \exp (\overline{w-p}+\bar{l})$. Then, evaluating the budget constraint at the point of expansion, we have $\exp (\bar{c})=\exp (\overline{w-p}+\bar{l})+\exp (\bar{\pi})$.

\section{A.1.3 The first order conditions for firms}

Firms set their prices optimally. The first order conditions can be written as

$$
\begin{gathered}
p_{\text {flex }, h, t}=w_{t}-a_{t}, \\
p_{\text {flex }, f, t}=\left(w_{t}^{*}-a_{t}^{*}+s_{t}\right), \\
p_{\text {prese }, h, t}=E_{t-1}\left(w_{t}-a_{t}\right)+\frac{1}{2} \operatorname{var}_{t-1}\left(w_{t}-a_{t}\right)+\operatorname{cov}_{t-1}\left(w_{t}-a_{t}, \tilde{d}_{t}+(\lambda-\omega) p_{h t}+\omega p_{t}+c_{t}\right) \\
p_{\text {preset }, h, t}=E_{t-1}\left(w_{t}-a_{t}-s_{t}\right)+\frac{1}{2} \operatorname{var}_{t-1}\left(w_{t}-a_{t}\right)-\frac{1}{2} \operatorname{var}_{t-1}\left(s_{t}\right) \\
\operatorname{cov}_{t-1}\left(w_{t}-a_{t}-s_{t}, \tilde{d}_{t}+(\lambda-\omega) p_{h t}+\omega p_{t}+c_{t}^{*}\right)
\end{gathered}
$$

Note that the conditional second moments in (A.9) and (A.10) are all constant over time, and will be treated as constant terms in subsequent linearizations.

Thus, the prices of each category of goods (3.19 and 3.20) can be expressed as following:

$$
\begin{aligned}
& p_{h, t}=\tau p_{\text {preset }, h, t}+(1-\tau) p_{\text {flex }, h, t}, \\
& p_{f, t}=\tau p_{\text {preset }, f, t}+(1-\tau) p_{\text {flex }, f, t} .
\end{aligned}
$$

Combining these two and suppressing the constants, we get the expression for price index: 


$$
p_{t}=\frac{1}{2} p_{h, t}+\frac{1}{2} p_{f, t}
$$

\section{A.1.4 Goods market clearing}

The goods market clearing condition, equation (3.21) can be linearized as

$$
l_{t}=\frac{1}{2}\left[-\omega\left(p_{h, t}-p_{t}\right)+c_{t}\right]+\frac{1}{2}\left[-\omega\left(p_{h, t}^{*}-p_{t}^{*}\right)+c_{t}^{*}\right]-a_{t} .
$$

\section{A.1.5 Other definitions}

In rewriting the budget constraint (3.13), we introduced human capital. Linearizing (3.9) gives us

$$
h_{t}=\frac{1-\beta}{\beta} \sum_{s=1}^{\infty} E_{t} \beta^{s}\left(w_{t+s}+l_{t+s}\right) .
$$

Using the definition of $R_{t}$ in equation (3.10), and the solution for $Q_{t}$ in equation (3.7), we can write

$$
r_{t}=(1-\beta) E_{t}\left(\sum_{s=0}^{\infty} \beta^{s} \pi_{t+s}\right)-(1-\beta) E_{t-1}\left(\sum_{s=0}^{\infty} \beta^{s} \pi_{t+s}\right)=(1-\beta) \sum_{s=0}^{\infty}\left(\beta^{s} \hat{E}_{t} \pi_{t+s}\right) .
$$

The log of home firms’ profits comes from linearizing (3.22):

$$
\pi_{t}=\frac{1}{1-\zeta}\left[c_{t}^{W}+p_{t}^{W}+\frac{1}{2} s_{t}+\frac{1}{2}(1-\omega)\left(p_{h, t}-p_{t}\right)+\frac{1}{2}(1-\omega)\left(p_{h, t}^{*}-p_{t}^{*}\right)-\zeta\left(w_{t}+l_{t}\right)\right] .
$$

Similarly,

$$
r_{t}^{H}=(1-\beta) \sum_{s=0}^{\infty}\left[\beta^{s} \hat{E}_{t}\left(w_{t+s}+l_{t+s}\right)\right]
$$

\section{A.2 Definition of Approximated Equilibrium}

\section{Definition B}

An approximated equilibrium is a set of sequences $\left\{c_{t}, l_{t}, w_{t}, r_{t}, r_{t}^{H}, \delta_{t}, \gamma_{t}, p_{t}, v_{t}, h_{t}\right\}$ and their foreign counterparts, and $\left\{s_{t}, f_{t}\right\}$ that solve the system of equation (A.1)-(A.6), (A.14)-(A.17), and their foreign counterparts, given sequences $\left\{m_{t}, m_{t}^{*}, a_{t}, a_{t}^{*}\right\}$ and initial conditions $a_{0}^{R}=0, m_{0}^{R}=0$, and $\gamma_{0}=\gamma_{0}^{*}=0$. An approximated equilibrium is a reduced form of Definition A. Most omitted part can be easily verified and should not be confusing. We present the solutions for $x_{t}$ and $x_{t}^{*}$ in the form of solutions for $x_{t}^{R}$ and $x_{t}^{W}$ to facilitate the demonstration that these satisfy the equilibrium conditions.

\section{A.3 Equilibrium Allocation}

We conjecture that the following allocation is an equilibrium. 


$$
\begin{aligned}
& l_{t}^{R}=\frac{\omega(1-\tau)-1}{1+\omega(1-\tau) \psi} a_{t}^{R}+\frac{\omega \tau}{1+\omega(1-\tau) \psi} \frac{\psi+1}{1+\omega \psi} E_{t-1} a_{t}^{R} \\
& =\frac{\omega(1-\tau)-1}{1+\omega(1-\tau) \psi} a_{t}^{R}+\frac{\omega \tau}{1+\omega(1-\tau) \psi} \frac{\psi+1}{1+\omega \psi} \vartheta_{R} a_{t-1}^{R} \\
& l_{t}^{W}=\frac{1}{\rho+(1-\tau) \psi}\left[(1-\tau-\rho) a_{t}^{W}+\tau m_{t}^{W}+\tau E_{t-1}\left(\frac{\rho(\psi+1)}{\rho+\psi} a_{t}^{W}-m_{t}^{W}\right)\right] \\
& =\frac{1}{\rho+(1-\tau) \psi}\left\{(1-\tau-\rho) a_{t}^{W}+\tau m_{t}^{W}+\tau\left[\frac{\rho(\psi+1)}{\rho+\psi} \vartheta_{W} a_{t-1}^{W}-m_{t-1}^{W}\right]\right\} \\
& w_{t}^{R}=\psi\left\{\frac{(1-\tau)(\omega-1)-\tau}{1+\omega(1-\tau) \psi} a_{t}^{R}+\frac{\omega \tau}{1+\omega(1-\tau) \psi} \frac{\psi+1}{1+\omega \psi} \vartheta_{R} a_{t-1}^{R}\right\}+m_{t}^{R} \\
& w_{t}^{W}=\frac{\psi}{\rho+(1-\tau) \psi}\left\{(1-\tau-\rho) a_{t}^{W}+\tau\left[\frac{\rho(\psi+1)}{\rho+\psi} \vartheta_{W} a_{t-1}^{W}-m_{t-1}^{W}\right]\right\}+\frac{\rho+\psi}{\rho+(1-\tau) \psi} m_{t}^{W} \\
& p_{t}^{R}=\tau m_{t-1}^{R}+(1-\tau) m_{t}^{R} \\
& p_{t}^{W}=-\frac{\rho \tau}{\rho+(1-\tau) \psi}\left[\frac{\rho(\psi+1)}{\rho+\psi} \vartheta_{W} a_{t-1}^{W}-m_{t-1}^{W}\right]-(1-\tau) \frac{\rho+\psi}{\rho+(1-\tau) \psi}\left[\frac{\rho(\psi+1)}{\rho+\psi} a_{t}^{W}-m_{t}^{W}\right] \\
& c_{t}^{R}=\frac{1}{\rho} \tau\left(m_{t}^{R}-m_{t-1}^{R}\right) \\
& c_{t}^{W}=\frac{\tau}{\rho+(1-\tau) \psi}\left[\frac{\rho(\psi+1)}{\rho+\psi} \vartheta_{W} a_{t-1}^{W}+\left(m_{t}^{W}-m_{t-1}^{W}\right)\right]+(1-\tau) \frac{1+\psi}{\rho+(1-\tau) \psi} a_{t}^{W} \\
& s_{t}=m_{t}^{R} \\
& f_{t}=m_{t-1}^{R} \text {. } \\
& r_{t}^{R}=(1-\beta)(\psi+1)\left[\frac{(1-\tau)(\omega-1)-\tau}{1+\omega(1-\tau) \psi}+\frac{1}{1-\zeta} \frac{\tau}{1+\omega(1-\tau) \psi}+\frac{\omega-1}{1+\omega \psi} \frac{\beta \vartheta_{R}}{1-\beta \vartheta_{R}}\right] \hat{a}_{t}^{R}+\hat{m}_{t}^{R} \\
& r_{t}^{W}=(1-\beta)(\psi+1)\left[\frac{(1-\tau)(1-\rho)}{\rho+(1-\tau) \psi}+\frac{\zeta}{1-\zeta} \frac{\tau \rho}{\rho+(1-\tau) \psi}+\frac{1-\rho}{\rho+\psi} \frac{\beta \vartheta_{W}}{1-\beta \vartheta_{W}}\right] \hat{a}_{t}^{W} \\
& +\left[1-\frac{\zeta}{1-\zeta} \frac{(1-\beta)(\psi+1) \tau}{\rho+(1-\tau) \psi}+\frac{1}{1-\zeta} \frac{(1-\beta)(1-\rho) \tau}{\rho+(1-\tau) \psi}\right] \hat{m}_{t}^{W} \\
& r_{t}^{H^{R}}=(1-\beta)(\psi+1)\left[\frac{(1-\tau)(\omega-1)-\tau}{1+\omega(1-\tau) \psi}+\frac{\omega-1}{1+\omega \psi} \frac{\beta \vartheta_{R}}{1-\beta \vartheta_{R}}\right] \hat{a}_{t}^{R}+\hat{m}_{t}^{R} \\
& r_{t}^{H^{W}}=(1-\beta)(\psi+1)\left[\frac{1-\tau-\rho}{\rho+(1-\tau) \psi}+\frac{1-\rho}{\rho+\psi} \frac{\beta \vartheta_{W}}{1-\beta \vartheta_{W}}\right] \hat{a}_{t}^{W}+\left[1+\frac{(1-\beta)(\psi+1) \tau}{\rho+(1-\tau) \psi}\right] \hat{m}_{t}^{W} \\
& \delta \equiv \delta_{t}=\frac{1}{2}\left(\frac{1}{\rho}-1\right) \tau
\end{aligned}
$$




$$
\begin{gathered}
\gamma \equiv \gamma_{t}=\gamma_{t}^{*}=\frac{1}{2} \frac{(\omega-1)\left[\frac{1-\tau}{1+\omega(1-\tau) \psi}+\frac{1}{1+\omega \psi} \frac{\beta \vartheta_{R}}{1-\beta \vartheta_{R}}\right]}{\frac{\tau \zeta}{1+\omega(1-\tau) \psi}+(1-\zeta)(\omega-1)\left[\frac{1-\tau}{1+\omega(1-\tau) \psi}+\frac{1}{1+\omega \psi} \frac{\beta \vartheta_{R}}{1-\beta \vartheta_{R}}\right]} \\
h_{t}^{R}=\frac{1-\beta}{\beta}\left[(\psi+1) \frac{\omega-1}{1+\omega \psi} \frac{\beta \vartheta_{R}}{1-\beta \vartheta_{R}} a_{t}^{R}\right]+m_{t}^{R} \\
h_{t}^{W}=\frac{1-\beta}{\beta}\left[(\psi+1) \frac{1-\rho}{\rho+\psi} \frac{\beta \vartheta_{w}}{1-\beta \vartheta_{w}} a_{t}^{W}\right]+m_{t}^{W} \\
v_{t}^{R}=\frac{-\zeta}{1-\zeta} \frac{1-\beta}{\beta}\left[(\psi+1) \frac{\omega-1}{1+\omega \psi} \frac{\beta \vartheta_{R}}{1-\beta \vartheta_{R}} a_{t}^{R}\right]+m_{t}^{R} \\
v_{t}^{W}=\frac{1-\beta}{\beta}\left[(\psi+1) \frac{1-\rho}{\rho+\psi} \frac{\beta \vartheta_{W}}{1-\beta \vartheta_{W}} a_{t}^{W}\right]+m_{t}^{W}
\end{gathered}
$$

Notice that this allocation replicates the allocation when a full set of state-contingent bonds is traded:

$$
\rho\left(c_{t}-c_{t}^{*}\right)=s_{t}+p_{t}^{*}-p_{t}
$$

\section{A.4 Proof}

We will show this allocation satisfies the equilibrium conditions.

\section{A.4.1 Fundamental Variables}

We now prove that the first order conditions for fundamental variables and labor market clearing conditions are in fact satisfied.

It is immediate to confirm that equations (A.18) - (A.21) satisfy equation (A.2). Likewise it is straightforward to check that (A.22) - (A.25) satisfy (A.1).

We can also verify that (A.18), (A.20) and (A.26) satisfy the relative version of the labor market clearing condition (A.14):

$$
l_{t}^{R}=-(1-\tau) \omega\left(w_{t}^{R}-a_{t}^{R}-s_{t}\right)-\tau \omega E_{t-1}\left(w_{t}^{R}-a_{t}^{R}-s_{t}\right)-a_{t}^{R} .
$$

It is tedious but straightforward to verify that (A.19) and (A.21) satisfy the world version of labor market clearing condition (A.14):

$$
l_{t}^{W}=c_{t}^{W}-a_{t}^{W} .
$$

Using equations (A.21) and (A.23), and using (A.20) and (A.26), we can show

$$
\begin{gathered}
p_{t}^{W}=\tau E_{t-1}\left(w_{t}^{W}-a_{t}^{W}\right)+(1-\tau)\left(w_{t}^{W}-a_{t}^{W}\right) \\
p_{t}^{R}=\tau E_{t-1} S_{t}+(1-\tau) s_{t}
\end{gathered}
$$


are satisfied. Note that the variance and covariance terms in (A.9) and (A.10) are constant, from the solutions above. Substituting equations (A.7) - (A.12) into (A.13), and suppressing constant terms, we see that (A.37) and (A.38) are the solutions to the world and relative versions of (A.13).

So far, we have proved equations (A.1), (A.2), (A.13), and (A.14) are satisfied.

\section{A.4.2 Returns on assets}

In order to show that this allocation in fact satisfies the first order conditions for asset holdings, we want to calculate the rate of return on assets - human capital and equities.

Since $w_{t+s}+l_{t+s}=(\psi+1)\left(l_{t+s}^{W}+\frac{1}{2} l_{t+s}^{R}\right)+m_{t+s}^{W}+\frac{1}{2} m_{t+s}^{R}$, the return on the human capital is

$$
\begin{aligned}
r_{t}^{H} & =(1-\beta) \sum_{s=0}^{\infty} \hat{E}_{t} \beta^{s}\left[(\psi+1)\left(l_{t+s}^{W}+\frac{1}{2} l_{t+s}^{R}\right)+m_{t+s}^{W}+\frac{1}{2} m_{t+s}^{R}\right] \\
& =(1-\beta)(\psi+1)\left\{\frac{1}{\rho+(1-\tau) \psi}\left[(1-\tau-\rho) \hat{a}_{t}^{W}+\tau \hat{m}_{t}^{W}\right]\right\} \\
& +(1-\beta)(\psi+1)\left\{\frac{1-\rho}{\rho+\psi} \frac{\beta \vartheta_{W}}{1-\beta \vartheta_{W}} \hat{a}_{t}^{W}+\frac{1}{2}\left[\frac{(1-\tau)(\omega-1)-\tau}{1+\omega(1-\tau) \psi}+\frac{\omega-1}{1+\omega \psi} \frac{\beta \vartheta_{R}}{1-\beta \vartheta_{R}}\right] \hat{a}_{t}^{R}\right\} \\
& +\left(\hat{m}_{t}^{W}+\frac{1}{2} \hat{m}_{t}^{R}\right) .
\end{aligned}
$$

Subtracting the foreign counterpart, we get equation (A.30). Adding the foreign counterpart gives us the solution to $r_{t}^{H^{w}}$.

Following similar step as in the return on human capital, we get the return on equity:

$$
\begin{aligned}
r_{t} & =(1-\beta)(\psi+1)\left\{\left[\frac{(1-\tau)(1-\rho)}{\rho+(1-\tau) \psi}+\frac{1}{1-\zeta} \frac{\tau \rho \zeta}{\rho+(1-\tau) \psi}+\frac{1-\rho}{\rho+\psi} \frac{\beta \vartheta_{W}}{1-\beta \vartheta_{W}}\right] \hat{a}_{t}^{W}\right. \\
& \left.+\frac{1}{2}\left[\frac{(1-\tau)(\omega-1)-\tau}{1+\omega(1-\tau) \psi}+\frac{1}{1-\zeta} \frac{\tau}{1+\omega(1-\tau) \psi}+\frac{\omega-1}{1+\omega \psi} \frac{\beta \vartheta_{R}}{1-\beta \vartheta_{R}}\right] \hat{a}_{t}^{R}\right\} \\
& +\left[1-\frac{\zeta}{1-\zeta} \frac{(1-\beta)(\psi+1) \tau}{\rho+(1-\tau) \psi}+\frac{1}{1-\zeta} \frac{(1-\beta)(1-\rho) \tau}{\rho+(1-\tau) \psi}\right] \hat{m}_{t}^{W}+\frac{1}{2} \hat{m}_{t}^{R}
\end{aligned}
$$

Subtracting the foreign counterpart, we get (A.28), and adding the foreign counterpart gives us that (A.29) is the solution for $r_{t}^{W}$. So, we have confirmed (A.16) and (A.17).

\section{A.4.3 Asset Allocation}

Since we replicate complete markets, these allocations should satisfy the first order conditions for the asset allocation as expressed in equations (3.4) and (3.15). We will prove that linearized 
version of them (A.3) - (A.4) are satisfied. From (A.26) and (A.27), we see $f_{t}=E_{t-1} s_{t}$. So, for equation (A.3) to be satisfied, we need

$$
\operatorname{cov}_{t-1}\left(m_{t}^{R}, s_{t}\right)=\operatorname{var}_{t-1}\left(s_{t}\right),
$$

which follows since $s_{t}=m_{t}^{R}$.

Since from (A.28) and (A.29), $r_{t}$ is i.i.d., we have $E_{t-1}\left(r_{t}-\left(m_{t}-m_{t-1}\right)\right)$ is constant. Likewise, using (A.26), $E_{t-1}\left(r_{t}^{*}+s_{t}-s_{t-1}-\left(m_{t}-m_{t-1}\right)\right)$ is constant. We can solve directly for these expectations from equations (A.4) and (A.5), using the covariances and variances implied by our solution in (A.18) - (A.33). But the following restriction links (A.4) and (A.5):

$$
\operatorname{cov}_{t-1}\left(-m_{t}, r_{t}\right)+\frac{1}{2} \operatorname{var}_{t-1}\left(r_{t}\right)=\operatorname{cov}_{t-1}\left(-m_{t}, s_{t}+r_{t}^{*}\right)+\frac{1}{2} \operatorname{var}_{t-1}\left(s_{t}+r_{t}^{*}\right)
$$

We verify this by using $r_{t}=r_{t}^{W}+\frac{1}{2} r_{t}^{R}$, and rewrite (A.46) as

$$
\operatorname{cov}_{t-1}\left(m_{t}^{W}+\frac{1}{2} m_{t}^{R}, r_{t}^{R}-m_{t}^{R}\right)+\frac{1}{2} \operatorname{var}_{t-1}\left(m_{t}^{R}+r_{t}^{W}-\frac{1}{2} r_{t}^{R}\right)-\frac{1}{2} \operatorname{var}_{t-1}\left(r_{t}^{W}+\frac{1}{2} r_{t}^{R}\right)=0 .
$$

We utilize orthogonality between world shocks and relative shocks to simplify the first term:

$$
\operatorname{cov}_{t-1}\left(m_{t}^{W}+\frac{1}{2} m_{t}^{R}, r_{t}^{R}-m_{t}^{R}\right)=\frac{1}{2} \operatorname{cov}_{t-1}\left(m_{t}^{R}, r_{t}^{R}-m_{t}^{R}\right) .
$$

The second and third terms can be expressed as

$$
\begin{aligned}
\frac{1}{2} \operatorname{var}_{t-1}\left(m_{t}^{R}+r_{t}^{W}-\frac{1}{2} r_{t}^{R}\right)-\frac{1}{2} \operatorname{var}_{t-1}\left(r_{t}^{W}+\frac{1}{2} r_{t}^{R}\right) & =\frac{1}{2} \operatorname{var}_{t-1}\left(m_{t}^{R}\right)-\frac{1}{2} \operatorname{cov}_{t-1}\left(m_{t}^{R}, r_{t}^{R}\right) \\
& =-\frac{1}{2} \operatorname{cov}_{t-1}\left(m_{t}^{R}, r_{t}^{R}-m_{t}^{R}\right)
\end{aligned}
$$

We confirm that this allocation in fact satisfies the first order conditions for asset allocations. So (A.3) - (A.5) are satisfied.

\section{A4.4 Human Wealth}

To verify that (A.34) and (A.35) provide the solution for human wealth (A.15), we use (A.18) - (A.21) to write

$$
\begin{aligned}
h_{t} & =\frac{1-\beta}{\beta} \sum_{s=1}^{\infty} E_{t} \beta^{s}\left(w_{t+s}+l_{t+s}\right) \\
& =\frac{1-\beta}{\beta} \sum_{s=1}^{\infty} \beta^{s}\left\{(\psi+1)\left[l_{t+s}^{W}+\frac{1}{2} l_{t+s}^{R}\right]+m_{t+s}^{W}+\frac{1}{2} m_{t+s}^{R}\right\} \\
& =\frac{1-\beta}{\beta} \sum_{s=1}^{\infty} \beta^{s}\left\{(\psi+1)\left[\frac{1-\rho}{\rho+\psi} \vartheta_{W}^{s} a_{t}^{W}+\frac{1}{2} \frac{\omega-1}{1+\omega \psi} \vartheta_{R}^{s} a_{t}^{R}\right]+m_{t}^{W}+\frac{1}{2} m_{t}^{R}\right\} \\
& =\frac{1-\beta}{\beta}\left\{(\psi+1)\left[\frac{1-\rho}{\rho+\psi} \frac{\beta \vartheta_{W}^{s}}{1-\beta \vartheta_{W}^{s}} a_{t}^{W}+\frac{1}{2} \frac{\omega-1}{1+\omega \psi} \frac{\beta \vartheta_{R}^{s}}{1-\beta \vartheta_{R}^{s}} a_{t}^{R}\right]+\frac{\beta}{1-\beta}\left[m_{t}^{W}+\frac{1}{2} m_{t}^{R}\right]\right\}
\end{aligned}
$$


Then subtracting the foreign counterpart of (A.50), we get (A.34), and adding the foreign counterpart gives us (A.35).

\section{A.4.5 Budget Constraint}

First, world budget constraint expressed in home currency is the following:

$$
p_{t}^{W}+c_{t}^{W}+\frac{\beta}{1-\beta}\left\{(1-\zeta) v_{t}^{W}+\zeta h_{t}^{W}\right\}=\frac{1}{1-\beta}(1-\zeta)\left(r_{t}^{W}+v_{t-1}^{W}\right)+\frac{1}{1-\beta} \zeta\left(r_{t}^{H^{W}}+h_{t-1}^{W}\right)
$$

where we have used $\gamma_{t}=\gamma_{t}^{*}$. We have also used $\delta_{t}\left(s_{t}-f_{t}\right)+\delta_{t}^{*}\left(-s_{t}+f_{t}\right)=0$, which requires $\delta_{t}=\delta_{t}^{*}$. This requires some explanation. The home currency earnings, expressed in home currency, from the forward market are $\tilde{\delta}_{t}\left(S_{t}-F_{t}\right)$. That means that the foreign currency earnings for the foreign country are $\tilde{\delta}_{t}\left(\frac{F_{t}}{S_{t}}-1\right)$, which can be written as $\tilde{\delta}_{t} F_{t}\left(\frac{1}{S_{t}}-\frac{1}{F_{t}}\right)$. So, the foreign budget constraint, symmetrically to the home budget constraint, will contain the term $\tilde{\delta}_{t}^{*}\left(\frac{1}{S_{t}}-\frac{1}{F_{t}}\right)$, where $\tilde{\delta}_{t}^{*}=\tilde{\delta}_{t} F_{t}$. Using this relationship, we can establish

$$
\delta_{t}^{*}=\frac{\tilde{\delta}_{t}^{*}}{F_{t} M_{t-1}^{*}} e^{\overline{m-p}-\bar{c}}=\frac{\tilde{\delta}_{t} F_{t}}{M_{t-1}} e^{\overline{m-p}-\bar{c}}=\delta_{t},
$$

where we have used (A.27), and $\overline{m-p}=\overline{m^{*}-p^{*}}$ and $\bar{c}=\bar{c}^{*}$.

The world budget constraint holds with any realization of $a_{t}^{W}$ and $m_{t}^{W}$ since equation (A.51) simply indicates that total world wealth carried over into the next period is equal to the value of previous wealth, plus returns, less world consumption. More explicitly, because

$$
v_{t}^{W}+h_{t}^{W}=\frac{1-\beta}{\beta} E_{t} \sum_{s=1}^{\infty} \beta^{s}\left(\pi_{t+s}^{W}+w_{t+s}^{W}+l_{t+s}^{W}\right)=\frac{1-\beta}{\beta} E_{t} \sum_{s=1}^{\infty} \beta^{s}\left(p_{t+s}^{W}+c_{t+s}^{W}\right),
$$

both sides of the equation are the sum of future consumption.

Finally, we examine relative budget constraint:

$$
\begin{aligned}
& p_{t}^{R}+c_{t}^{R}-s_{t}+\frac{\beta}{1-\beta}\left[(1-\zeta) v_{t}^{R}+\zeta h_{t}^{R}-s_{t}\right] \\
& =\frac{1}{1-\beta}(1-\zeta)\left[r_{t}^{R}-s_{t}+v_{t-1}^{R}-\left(\gamma_{t}+\gamma_{t}^{*}\right)\left(r_{t}^{R}-\hat{s}_{t}\right)\right]+\frac{1}{1-\beta} \zeta\left(r_{t}^{H^{R}}-s_{t}+h_{t-1}^{R}\right)+2 \delta_{t} \hat{s}_{t}
\end{aligned}
$$

Direct substitution from the solutions verifies this equation, but it is helpful to break this down into steps.

Using $\gamma=\gamma_{t}=\gamma_{t}^{*}$, and the solutions for $c_{t}^{R}, p_{t}^{R}$, and $s_{t}$, we can write 


$$
\begin{aligned}
& \left(\frac{1}{\rho}-1\right) \tau \hat{m}_{t}^{R}+\frac{\beta}{1-\beta}\left[(1-\zeta) v_{t}^{R}+\zeta h_{t}^{R}-m_{t}^{R}\right] \\
& \left.=\frac{1}{1-\beta}(1-\zeta)\left[r_{t}^{R}-\hat{m}_{t}^{R}-2 \gamma_{t}\left(r_{t}^{R}-\hat{m}_{t}^{R}\right)\right]\right] \frac{1}{1-\beta} \zeta\left(r_{t}^{H^{R}}-\hat{m}_{t}^{R}\right)+2 \delta_{t} \hat{m}_{t}^{R} \\
& +\frac{1}{1-\beta}\left[(1-\zeta) v_{t-1}^{R}+\zeta h_{t-1}^{R} m_{t-1}^{R}\right]
\end{aligned}
$$

Using relative returns (A.28) - (A.31), we get

$$
\begin{aligned}
& {\left[\left(\frac{1}{\rho}-1\right) \tau-2 \delta_{t}\right] \hat{m}_{t}^{R}+\frac{\beta}{1-\beta}\left[(1-\zeta) v_{t}^{R}+\zeta h_{t}^{R}-m_{t}^{R}\right]} \\
& =\left\{\left(1-2 \gamma_{t}\right)(1-\zeta)(\psi+1)\left[\frac{(1-\tau)(\omega-1)-\tau}{1+\omega(1-\tau) \psi}+\frac{1}{1-\zeta} \frac{\tau}{1+\omega(1-\tau) \psi}+\frac{\omega-1}{1+\omega \psi} \frac{\beta \vartheta_{R}}{1-\beta \vartheta_{R}}\right]\right\} \hat{a}_{t}^{R} \\
& +\left\{\zeta(\psi+1)\left[\frac{(1-\tau)(\omega-1)-\tau}{1+\omega(1-\tau) \psi}+\frac{\omega-1}{1+\omega \psi} \frac{\beta \vartheta_{R}}{1-\beta \vartheta_{R}}\right]\right\} \hat{a}_{t}^{R}+\frac{1}{1-\beta}\left[(1-\zeta) v_{t-1}^{R}+\zeta h_{t-1}^{R}-m_{t-1}^{R}\right]
\end{aligned}
$$

By substituting expressions for $\delta_{t}$ and $\gamma_{t}$ from (A.32) and (A.33). into (A.56), we get

$$
\beta\left[(1-\zeta) v_{t}^{R}+\zeta h_{t}^{R}-m_{t}^{R}\right]=(1-\zeta) v_{t-1}^{R}+\zeta h_{t-1}^{R}-m_{t-1}^{R} .
$$

But (A.34) and (A.36) give us

$$
(1-\zeta) v_{t}^{R}+\zeta h_{t}^{R}-m_{t}^{R}=0,
$$

so (A.57) holds.

We have verified that equations (A.1)-(A.6) and (A.14)-(A.17) are satisfied. 
Table 1 - List of Notation

\begin{tabular}{|c|c|}
\hline$\beta$ & Discount factor \\
\hline$\rho$ & Risk aversion parameter \\
\hline$\chi$ & Real balance parameter \\
\hline$\psi$ & Labor supply parameter \\
\hline$\omega$ & Elasticity of substitution between Home and Foreign goods \\
\hline$\lambda$ & Elasticity of substitution among Home goods and Foreign goods \\
\hline$\vartheta_{R}, \vartheta_{W}$ & Persistence of the technology shocks \\
\hline$\zeta$ & Labor's share in national income \\
\hline$\gamma_{h}$ & Home equity share in the equity portfolio \\
\hline$\gamma=\gamma_{f}$ & Foreign equity share in the equity portfolio \\
\hline$\tilde{\delta}$ & Number of forward contracts \\
\hline$\delta$ & Normalized number of forward contracts \\
\hline$\tau$ & Ratio of firms setting price in advance in the dynamic model \\
\hline$\Pi_{t}$ & Nominal profit of Home firms = dividend \\
\hline$A_{t}$ & Productivity \\
\hline$C_{t}$ & Consumption basket \\
\hline$C_{h, t}$ & Consumption aggregate of Home-produced goods \\
\hline$C_{f, t}$ & Consumption aggregate of Foreign-produced goods \\
\hline$C_{h, t}(i)$ & Consumption of Home-produced good of variety $i$ \\
\hline$C_{f, t}(i)$ & Consumption of Foreign-produced good of variety $i$ \\
\hline$F_{t}$ & Forward rate for delivery at time $t$ (set at $t-1$ ) \\
\hline$H_{t}$ & Value of human capital \\
\hline$L_{t}$ & Employment \\
\hline$M_{t}$ & Money balances \\
\hline$P_{t}$ & Price of consumption basket \\
\hline$P_{h, t}$ & Price of consumption aggregate of Home-produced goods \\
\hline$P_{f, t}$ & Price of consumption aggregate of Foreign-produced goods \\
\hline$P_{h, t}(i)$ & Price of consumption of Home-produced good of variety $i$ \\
\hline$P_{f, t}(i)$ & Price of consumption of Foreign-produced good of variety $i$ \\
\hline$Q_{t}$ & Price of home equity \\
\hline$R_{t}$ & Return on home equity \\
\hline$R_{t}^{H}$ & Return on human capital \\
\hline$S_{t}$ & Nominal exchange rate \\
\hline$T r_{t}$ & Transfer from government \\
\hline$V_{t}$ & Value of equity portfolio \\
\hline$W_{t}$ & Nominal wage rate \\
\hline$Y_{t}$ & Output of Home goods \\
\hline
\end{tabular}


Table 2

\section{Correlation of Returns on Home Equities with Returns to Human Capital}

\begin{tabular}{l} 
Average duration of $\mathbf{4}$ quarters \\
corr(a,a*) \\
\cline { 2 - 9 }
\end{tabular}

Average duration of 2 quarters

\begin{tabular}{|c|c|c|c|c|c|c|c|}
\hline \multirow[b]{2}{*}{$\operatorname{corr}\left(\mathbf{a}, \mathbf{a}^{*}\right)$} & \multicolumn{7}{|c|}{ Standard Deviation of Productivity Shock Relative to Monetary Shock } \\
\hline & 0.01 & 0.5 & 1 & 2 & 4 & 8 & 100 \\
\hline 0 & 0.996 & 0.993 & 0.984 & 0.968 & 0.954 & 0.949 & 0.947 \\
\hline 0.25 & 0.996 & 0.993 & 0.986 & 0.974 & 0.968 & 0.968 & 0.968 \\
\hline 0.5 & 0.996 & 0.993 & 0.987 & 0.980 & 0.979 & 0.981 & 0.982 \\
\hline 0.75 & 0.996 & 0.994 & 0.989 & 0.985 & 0.988 & 0.991 & 0.992 \\
\hline 0.99 & 0.996 & 0.994 & 0.990 & 0.989 & 0.995 & 0.998 & 1.000 \\
\hline
\end{tabular}

Notes: Numbers on the left-hand-column refer to the correlation between innovations in home and foreign productivity, $\hat{a}_{t}$ and $\hat{a}_{t}^{*}$. Numbers along the top row are the standard deviation of innovations in productivity relative to the standard deviation of innovations to the money supplies. The numbers reported in the tables are the correlation of home equity return with the return to home human capital. 
Table 3

\section{Correlation of Relative Returns on Equities with Returns to Human Capital}

\section{Average duration of 4 quarters}

\begin{tabular}{|c|c|c|c|c|c|c|c|}
\hline \multirow[b]{2}{*}{$\operatorname{corr}\left(a, a^{*}\right)$} & \multicolumn{7}{|c|}{ Standard Deviation of Productivity Shock Relative to Monetary Shock } \\
\hline & 0.01 & 0.5 & 1 & 2 & 4 & 8 & 100 \\
\hline 0 & 0.683 & 0.651 & 0.572 & 0.378 & 0.125 & -0.039 & -0.123 \\
\hline 0.25 & 0.683 & 0.649 & 0.565 & 0.376 & 0.142 & -0.012 & -0.095 \\
\hline 0.5 & 0.683 & 0.646 & 0.560 & 0.377 & 0.162 & 0.016 & -0.071 \\
\hline 0.75 & 0.683 & 0.644 & 0.555 & 0.380 & 0.187 & 0.052 & -0.046 \\
\hline 0.99 & 0.683 & 0.641 & 0.551 & 0.384 & 0.219 & 0.111 & -0.005 \\
\hline
\end{tabular}

Average duration of 2 quarters

\begin{tabular}{|c|c|c|c|c|c|c|c|}
\hline \multirow[b]{2}{*}{$\operatorname{corr}\left(a, a^{*}\right)$} & \multicolumn{7}{|c|}{ Standard Deviation of Productivity Shock Relative to Monetary Shock } \\
\hline & 0.01 & 0.5 & 1 & 2 & 4 & 8 & 100 \\
\hline 0 & 0.695 & 0.672 & 0.613 & 0.464 & 0.247 & 0.068 & -0.067 \\
\hline 0.25 & 0.695 & 0.667 & 0.600 & 0.444 & 0.239 & 0.078 & -0.051 \\
\hline 0.5 & 0.695 & 0.663 & 0.589 & 0.428 & 0.235 & 0.089 & -0.038 \\
\hline 0.75 & 0.695 & 0.659 & 0.578 & 0.415 & 0.233 & 0.103 & -0.024 \\
\hline 0.99 & 0.695 & 0.656 & 0.569 & 0.404 & 0.233 & 0.121 & 0.002 \\
\hline
\end{tabular}

Notes: Numbers on the left-hand-column refer to the correlation between innovations in home and foreign productivity, $\hat{a}_{t}$ and $\hat{a}_{t}^{*}$. Numbers along the top row are the standard deviation of innovations in productivity relative to the standard deviation of innovations to the money supplies. The numbers reported in the tables are the correlation of home relative to foreign equity return with the return to home human capital. 


\section{Table 4a}

\section{Correlations of Real Variables}

Average duration of 4 quarters

correlation between home and foreign consumption growth

\begin{tabular}{r|rrrrrrr}
\hline & \multicolumn{7}{|c}{ Standard Deviation of Technology Shocks Relative to Monetary Shocks } \\
\cline { 1 - 7 } corr(a,a*) & 0.01 & 0.5 & 1 & 2 & 4 & 8 & 100 \\
\cline { 2 - 7 } 0.00 & -0.095 & 0.018 & 0.249 & 0.614 & 0.869 & 0.964 & 1.000 \\
0.25 & -0.095 & 0.042 & 0.304 & 0.668 & 0.892 & 0.971 & 1.000 \\
0.50 & -0.095 & 0.066 & 0.351 & 0.708 & 0.909 & 0.976 & 1.000 \\
0.75 & -0.095 & 0.088 & 0.393 & 0.740 & 0.921 & 0.979 & 1.000 \\
0.99 & -0.095 & 0.108 & 0.428 & 0.765 & 0.930 & 0.982 & 1.000 \\
\hline
\end{tabular}

correlation between home and foreign output growth

\begin{tabular}{r|rrrrrrr}
\hline & \multicolumn{8}{|c}{ Standard Deviation of Technology Shocks Relative to Monetary Shocks } \\
\cline { 2 - 7 } corr(a,a*) & 0.01 & 0.5 & 1 & 2 & 4 & 8 & 100 \\
\cline { 3 - 7 } 0.00 & 1.000 & 0.599 & 0.231 & 0.002 & -0.078 & -0.100 & -0.107 \\
0.25 & 1.000 & 0.696 & 0.412 & 0.233 & 0.170 & 0.153 & 0.147 \\
0.50 & 1.000 & 0.795 & 0.601 & 0.476 & 0.431 & 0.419 & 0.415 \\
0.75 & 1.000 & 0.897 & 0.796 & 0.731 & 0.708 & 0.701 & 0.699 \\
0.99 & 1.000 & 0.996 & 0.992 & 0.989 & 0.988 & 0.988 & 0.988 \\
\hline
\end{tabular}

correlation between home consumption and output growth

\begin{tabular}{r|rrrrrrr}
\hline & \multicolumn{7}{|c}{ Standard Deviation of Technology Shocks Relative to Monetary Shocks } \\
\cline { 2 - 7 } corr(a,a*) & 0.01 & 0.5 & 1 & 2 & 4 & 8 & 100 \\
\cline { 2 - 7 } 0.00 & 0.673 & 0.638 & 0.620 & 0.636 & 0.656 & 0.665 & 0.668 \\
0.25 & 0.673 & 0.665 & 0.679 & 0.717 & 0.744 & 0.754 & 0.757 \\
0.50 & 0.673 & 0.692 & 0.735 & 0.794 & 0.826 & 0.837 & 0.841 \\
0.75 & 0.673 & 0.718 & 0.791 & 0.868 & 0.906 & 0.917 & 0.922 \\
0.99 & 0.673 & 0.744 & 0.843 & 0.937 & 0.979 & 0.992 & 0.997 \\
\hline
\end{tabular}




\section{Table 4b}

\section{Correlations of Real Variables}

\section{Average duration of 2 quarters}

correlation between home and foreign consumption growth

\begin{tabular}{r|rrrrrrr}
\hline & \multicolumn{7}{|c}{ Standard Deviation of Technology Shocks Relative to Monetary Shocks } \\
\cline { 2 - 7 } $\operatorname{corr}\left(\mathbf{a}, \mathbf{a}^{*}\right)$ & 0.01 & 0.5 & 1 & 2 & 4 & 8 & 100 \\
0.00 & -0.095 & 0.018 & 0.249 & 0.614 & 0.869 & 0.964 & 1.000 \\
0.25 & -0.095 & 0.042 & 0.304 & 0.668 & 0.892 & 0.971 & 1.000 \\
0.50 & -0.095 & 0.066 & 0.351 & 0.708 & 0.909 & 0.976 & 1.000 \\
0.75 & -0.095 & 0.088 & 0.393 & 0.740 & 0.921 & 0.979 & 1.000 \\
0.99 & -0.095 & 0.108 & 0.428 & 0.765 & 0.930 & 0.982 & 1.000 \\
\hline
\end{tabular}

correlation between home and foreign output growth

\begin{tabular}{r|rrrrrrr}
\hline & \multicolumn{7}{|c}{ Standard Deviation of Technology Shocks Relative to Monetary Shocks } \\
\cline { 2 - 7 } corr(a,a*) & 0.01 & 0.5 & 1 & 2 & 4 & 8 & 100 \\
\cline { 3 - 7 } 0.00 & 1.000 & 0.483 & 0.070 & -0.161 & -0.238 & -0.259 & -0.266 \\
0.25 & 1.000 & 0.601 & 0.267 & 0.073 & 0.007 & -0.011 & -0.017 \\
0.50 & 1.000 & 0.727 & 0.485 & 0.339 & 0.288 & 0.275 & 0.270 \\
0.75 & 1.000 & 0.859 & 0.728 & 0.645 & 0.615 & 0.607 & 0.605 \\
0.99 & 1.000 & 0.994 & 0.988 & 0.985 & 0.983 & 0.983 & 0.983 \\
\hline
\end{tabular}

correlation between home consumption and output growth

\begin{tabular}{r|rrrrrrr}
\hline & \multicolumn{7}{|c}{ Standard Deviation of Technology Shocks Relative to Monetary Shocks } \\
\cline { 2 - 7 } corr(a,a*) & 0.01 & 0.5 & 1 & 2 & 4 & 8 & 100 \\
\cline { 3 - 7 } 0.00 & 0.673 & 0.614 & 0.578 & 0.582 & 0.597 & 0.603 & 0.606 \\
0.25 & 0.673 & 0.646 & 0.643 & 0.669 & 0.690 & 0.698 & 0.701 \\
0.50 & 0.673 & 0.678 & 0.708 & 0.756 & 0.784 & 0.793 & 0.797 \\
0.75 & 0.673 & 0.711 & 0.776 & 0.846 & 0.881 & 0.892 & 0.896 \\
0.99 & 0.673 & 0.743 & 0.842 & 0.936 & 0.978 & 0.991 & 0.996 \\
\hline
\end{tabular}




\section{Table 5}

\section{Foreign equity share regressions}

\section{OLS}

Dependent Variable

Slope Intercept

Foreign

Stocks/STOCK $\quad$ coeffcient $\quad-0.00322 \quad 0.018641$

adj std $\quad 0.004019 \quad 0.003227$

Foreign

Stocks/EQUITY coeffcient $\quad-0.00445 \quad 0.01137$

adj std $\quad 0.002467 \quad 0.001981$

Foreign Stocks/FIN $\quad$ coeffcient $\quad-0.00314 \quad 0.00688$

adj std $\quad 0.00151 \quad 0.001213$

Notes: \# of observation 22210/5. There are 5 replicated samples for each sample. We report OLS standard errors adjusted as suggested by the Survey of Consumer Finance, by multiplying unadjusted standard deviation by square root of 5 . The independent variable is truncated labor share 